\title{
Fluorescence Quenching in J-aggregates Through the Formation of Unusual Metastable Dimers
}

\author{
Felix Witte, ${ }^{1 *}$ Philipp Rietsch, Shreya Sinha, Alexander Krappe, Jan-O. Joswig, \\ Jan P. Götze, Nithiya Nirmalananthan-Budau, Ute Resch-Genger, Siegfried Eigler, and Beate Paulus ${ }^{1}$
}

\footnotetext{
${ }^{1}$ F. Witte, J.-O. Joswig, J. P. Götze, Prof. Dr. B. Paulus Institute of Chemistry and Biochemistry

Freie Universität Berlin

Arnimallee 22, 14195 Berlin, Germany

E-mail: jf.witte@fu-berlin.de

${ }^{2}$ P. Rietsch, A. Krappe, Prof. Dr. S. Eigler

Institute of Chemistry and Biochemistry

Freie Universität Berlin

Takustr. 3, 14195 Berlin, Germany

${ }^{3}$ S. Sinha, N. Nirmalananthan-Budau, U. Resch-Genger

Division Biophotonics

Federal Institute for Material Research and Testing (BAM)

Richard-Willstätter-Straße 11, 12489 Berlin, Germany
} 


\section{Contents}

1 General information $\quad$ S3

2 Synthetic procedures and spectral characterization $\quad$ S3

$2.1 \quad 1 \ldots \ldots \ldots \ldots \ldots \ldots$

$2.21 \mathrm{Me} \ldots \ldots \ldots \ldots \ldots \ldots \ldots \ldots \ldots$

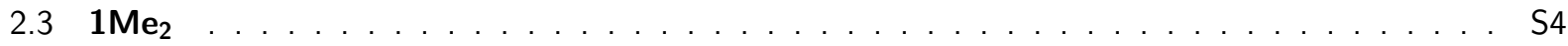

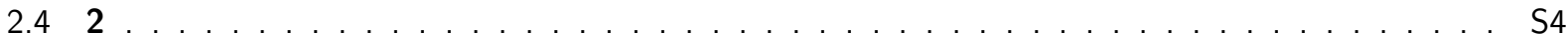

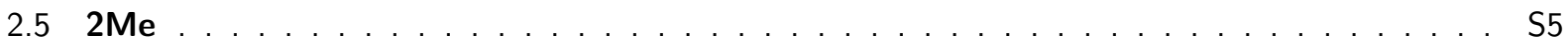

$2.62 \mathrm{Me}_{2} \ldots \ldots \ldots \ldots \ldots \ldots \ldots \ldots$

$\begin{array}{lll}3 \mathrm{UV} / \mathrm{V} \text { is titration experiments } & \mathrm{S7}\end{array}$

3.1 Temperature dependence . . . . . . . . . . . . . . . . . . . . . . . . S10

3.2 Effect of polar additives . . . . . . . . . . . . . . . . . . . . . . . . . S11

4 Excitation emission matrices $\quad$ S13

$\begin{array}{llr}5 & \text { Computational Details } & \text { S14 }\end{array}$

6 Additional DADQ aggregation properties $\mathbf{S 1 5}$

6.1 Extension to trimers and tetramers . . . . . . . . . . . . . . . . . . . . . . .

$\begin{array}{llr}7 & \text { Excited state calculations } & \mathbf{S 2 0}\end{array}$

$\begin{array}{llr}8 & \text { AIMD simulations } & \mathbf{S 2 5}\end{array}$

9 Coordinates of molecular structures of all dimers $\quad$ S26 


\title{
1 General information
}

All reagents were purchased from commercial sources and used without further purification. Dry solvents were purchased from Acros Organics. ALUGRAM Xtra SIL G/UV254 plates by Macherey-Nagel were used for thin-layer chromatography. Isolation of products by chromatography was performed with silica from Macherey-Nagel Silica $60 \mathrm{M}, 0.04-0.063 \mathrm{~mm})$. NMR spectra were recorded on a JOEL ECX $400\left({ }^{1} \mathrm{H} 400 \mathrm{MHz},{ }^{13} \mathrm{C} 101 \mathrm{MHz}\right), \mathrm{JEOL}$ Eclipse+ $500\left({ }^{1} \mathrm{H} 500 \mathrm{MHz},{ }^{13} \mathrm{C} 126 \mathrm{MHz}\right)$ and BRUKER AVANCE $700\left({ }^{1} \mathrm{H} 700 \mathrm{MHz},{ }^{13} \mathrm{C} 176 \mathrm{MHz}\right)$ spectrometer at $25{ }^{\circ} \mathrm{C}$. The chemical shifts $\delta$ are calibrated on the respective solvent peak as internal standard. All shifts are reported in ppm and NMR multiplicities are abbreviated as s (singlet), d (duplet), t (triplet), $\mathrm{m}$ (multiplet). Coupling constants $\mathrm{J}$ are reported in $\mathrm{Hz}$. UV/Vis spectra were recorded on a Cary 50 Bio photospectrometer (Varian). Fluorescence spectra were recorded on a LS 50 B luminescence spectrometer from PerkinElmer. UV/Vis and Fluorescence spectra were measured in quartz glass cuvettes with $1 \mathrm{~cm}$ path length. IR Spectra were recorded on a FT/IR 4100 spectrometer from JASCO. Elemental analysis were performed on an VARIO EL from Elementar.

\section{Synthetic procedures and spectral characterization}

2-(4-(cyano(pyrrolidin-1-yl)methylene)cyclohexa-2,5-dien-1-ylidene)malononitrile (PTCNQ) and compounds 1, 2, and $2 \mathbf{M e}_{2}$ were synthesized as reported previously. ${ }^{[1]}$

\subsection{2-(4-(imidazolidin-2-ylidene)cyclohexa-2,5-dien-1-ylidene)malononitrile (1)}<smiles></smiles>

Ethylenediamine $\left(26.6 \mathrm{mg}, 0.44 \mathrm{mmol}, 1 \mathrm{eq}\right.$.) was added to a $40{ }^{\circ} \mathrm{C}$ warm solution of PTCNQ (110 mg, $0.44 \mathrm{mmol}, 1$ eq.) in acetonitrile $(10 \mathrm{~mL})$. The solution turned deep green immediately and to yellow in the next minutes. The solution was stirred $a 0^{\circ} \mathrm{C}$ for 4 hours and then cooled to room temperature. The precipitate was filtered off and washed with cooled acetonitrile $(3 \times 5 \mathrm{~mL})$ to yield the product as a yellow fine-grain powder (73.4 $\mathrm{mg}, 0.35 \mathrm{mmol}, 79 \%$ ).

${ }^{1} \mathbf{H}$ NMR $\left(500 \mathrm{MHz}\right.$, DMSO-d 6 , RT): $\delta(\mathrm{ppm})=9.76(\mathrm{~s}, 2 \mathrm{H}, 9), 7.57\left(\mathrm{~d},{ }^{3} \mathrm{~J}=5.0 \mathrm{~Hz}, 2 \mathrm{H}, 2\right), 6.82\left(\mathrm{~d},{ }^{3} \mathrm{~J}=\right.$ $5.0 \mathrm{~Hz}, 2 \mathrm{H}, 2$ ), 3.87 (bs, $4 \mathrm{H}, 7$ ).

${ }^{13} \mathrm{C}$ NMR $\left(125 \mathrm{MHz}, \mathrm{DMSO}-\mathrm{d}_{6}, \mathrm{RT}\right): \delta(\mathrm{ppm})=164.73(1 \mathrm{C}, 6), 150.53(1 \mathrm{C}, 5), 129.48(1 \mathrm{C}, 1), 124.40(2 \mathrm{C}$, 2), $117.90(2 \mathrm{C}, 3), 108.73(2 \mathrm{C}, 8), 44.36(1 \mathrm{C}, 4), 35.42(2 \mathrm{C}, 7)$.

FT-IR (ATR) $\tilde{\nu}\left(\mathrm{cm}^{-1}\right)$ : $3084(\mathrm{w}), 3022(\mathrm{vw}), 3009$ (vw), 2183 (s), 2144 (vs), 1594 (s), 1580 (s), 1507 (s), 1332 (s), $1282(\mathrm{~s}), 1236(\mathrm{w}), 1199(\mathrm{~m}), 952(\mathrm{w}), 873(\mathrm{~s}), 747(\mathrm{~m})$.

UV/Vis (DMSO) $\lambda_{\max } \mathrm{nm}\left(\varepsilon\left[\mathrm{Lmol}^{-1} \mathrm{~cm}^{-1}\right]\right): 405$ (22800).

UV/Vis (ACN) $\lambda_{\max } \mathrm{nm}\left(\varepsilon\left[\mathrm{Lmol}^{-1} \mathrm{~cm}^{-1}\right]\right): 357$ (4000), 409 (4000).

UV/Vis (DMF) $\lambda_{\max } \mathrm{nm}\left(\varepsilon\left[\mathrm{Lmol}^{-1} \mathrm{~cm}^{-1}\right]\right): 363(13000), 410(18000)$

UV/Vis (Methanol) $\lambda_{\max } \mathrm{nm}\left(\varepsilon\left[\mathrm{Lmol}^{-1} \mathrm{~cm}^{-1}\right]\right): 395$ (36875).

MS (EI): $\mathrm{m} / \mathrm{z}=210.1(100)[\mathrm{MH}]^{+} ; 209.1$ (50); 182.1 (40); 181.1 (100); 155.1 (15); 141.0 (15); 114 (15).

EA: $\mathrm{C}_{12} \mathrm{H}_{10} \mathrm{~N}_{4}$; calc.: $\mathrm{C}, 68.56 ; \mathrm{N}, 26.65 ; \mathrm{H}, 4.79$ meas.: $\mathrm{C}, 68.22 ; \mathrm{N}, 25.76 ; \mathrm{H}, 5.03$.

\subsection{2-(4-(1-Methylimidazolidin-2-yliden)cyclohexa-2,5-dien-1- yliden)malononitrile (1Me)}

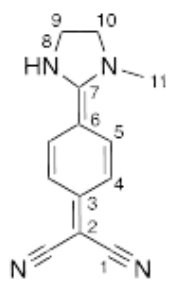

\begin{abstract}
$\mathrm{N}$-Methylethylendiamin (63 mg, $0.074 \mathrm{~mL}, 0.81 \mathrm{mmol}, 1$ eq.) was added to a $40{ }^{\circ} \mathrm{C}$ warm solution of PTCNQ (200 mg, $0.81 \mathrm{mmol}, 1$ eq.) in $25 \mathrm{~mL}$ acetonitrile. The solution turned green after addition and a yellow solid precipitated after approximately 30 minutes. The solution was stirred at $70{ }^{\circ} \mathrm{C}$ for 4 hours and then cooled to room temperature. The precipitate was filtered off and washed with cooled acetonitrile $(3 \times 10 \mathrm{~mL})$ to yield the product as a green powder $(141.7 \mathrm{mg}, 0.63 \mathrm{mmol}, 78 \%)$.
\end{abstract}

\footnotetext{
${ }^{1} \mathbf{H}$ NMR $(700 \mathrm{MHz}$, DMSO-d $6, \mathrm{RT}): \delta(\mathrm{ppm})=9.59(\mathrm{~s}, 1 \mathrm{H}, 8), 7.36\left(\mathrm{~d},{ }^{3} \mathrm{~J}=8.5 \mathrm{~Hz}, 2 \mathrm{H}, 4\right), 6.85(\mathrm{~d}$, $\left.{ }^{3} \mathrm{~J}=8.5 \mathrm{~Hz}, 2 \mathrm{H}, 5\right), 3.98\left(\mathrm{t},{ }^{3} \mathrm{~J}=9.8 \mathrm{~Hz}, 2 \mathrm{H}, 9\right), 3.80\left(\mathrm{t},{ }^{3} \mathrm{~J}=9.8 \mathrm{~Hz}, 2 \mathrm{H}, 10\right), 3.14(\mathrm{~s}, 3 \mathrm{H}, 11)$.

${ }^{13} \mathrm{C}$ NMR $\left(176 \mathrm{MHz}, \mathrm{DMSO}-\mathrm{d}_{6}, \mathrm{RT}\right): \delta(\mathrm{ppm})=165.66(1 \mathrm{C}, 2), 148.99(1 \mathrm{C}, 7), 129.68(1 \mathrm{C}, 3), 123.36(2 \mathrm{C}$, 4), $117.46(2 \mathrm{C}, 5), 108.63(2 \mathrm{C}, 1), 52.60$ (1C, 6), $41.83(1 \mathrm{C}, 9), 35.05(1 \mathrm{C}, 10), 33.59(1 \mathrm{C}, 11)$
} 
FT-IR (ATR) $\tilde{\nu}\left(\mathrm{cm}^{-1}\right): 3164(\mathrm{w}), 2177$ (s), 2147 (s), 1570 (s), 1501 (s), 1378 (m), 1330 (s), 1300 (m), 1286 $(\mathrm{m}), 1190(\mathrm{~s}), 944(\mathrm{~m}), 836(\mathrm{~s})$.

UV/Vis (DMSO) $\lambda_{\max } \mathrm{nm}\left(\varepsilon\left[\mathrm{Lmol}^{-1} \mathrm{~cm}^{-1}\right]\right): 390$ (29000).

UV/Vis (ACN) $\lambda_{\max } \mathrm{nm}\left(\varepsilon\left[\mathrm{Lmol}^{-1} \mathrm{~cm}^{-1}\right]\right): 391(21200)$.

UV/Vis (DMF) $\lambda_{\max } \mathrm{nm}\left(\varepsilon\left[\mathrm{Lmol}^{-1} \mathrm{~cm}^{-1}\right]\right): 351(17700)$.

UV/Vis (Methanol) $\lambda_{\max } \mathrm{nm}\left(\varepsilon\left[\mathrm{Lmol}^{-1} \mathrm{~cm}^{-1}\right]\right): 380(24600)$.

UV/Vis (THF) $\lambda_{\max } \mathrm{nm}\left(\varepsilon\left[\mathrm{Lmol}^{-1} \mathrm{~cm}^{-1}\right]\right): 425(18800)$.

MS (ESI): $\mathrm{m} / \mathrm{z}=471.20(25)[2 \mathrm{M}-\mathrm{Na}]^{+}, 263.07(32)[\mathrm{M}-\mathrm{K}]^{+}, 247.09(82)[\mathrm{M}-\mathrm{Na}]^{+}, 225.11(35)[\mathrm{M}]^{+}$.

EA*: $\mathrm{C}_{13} \mathrm{H}_{12} \mathrm{~N}_{4}$; calc.: $\mathrm{C}, 69.62 ; \mathrm{N}, 24.98 ; \mathrm{H}, 5.39$; meas.: $\mathrm{C}, 67.50 ; \mathrm{N}, 23.85 ; \mathrm{H}, 5.207$.

*Small amounts of acetonitrile and water may be responsible for the deviations of calculated and measured values.

\title{
2.3 2-(4-(1,3-Dimethylimidazolidin-2-yliden)cyclohexa-2,5-dien-1- yliden)malononitrile $\left(1 \mathrm{Me}_{2}\right)$
}<smiles>CN1CCN(C)C1=C1C=CC(C#N)C=C1</smiles>

$N, N^{\prime}$-Dimethylethylendiamin $(71 \mathrm{mg}, 0.087 \mathrm{~mL}, 0.81 \mathrm{mmol}, 1$ eq. $)$ was added to a $40{ }^{\circ} \mathrm{C}$ warm solution of PTCNQ (200 mg, $0.81 \mathrm{mmol}, 1$ eq.) in $25 \mathrm{~mL}$ acetonitrile. The solution was stirred at $70{ }^{\circ} \mathrm{C}$ for 4 hours and then cooled to room temperature. The precipitate was filtered off and washed with cooled acetonitrile $(3 \times 10 \mathrm{~mL})$ to yield the product as a yellow powder $(75.7 \mathrm{mg}, 0.32 \mathrm{mmol}, 39 \%)$.

${ }^{1} \mathbf{H}$ NMR $(700 \mathrm{MHz}$, DMSO-d $6, \mathrm{RT}): \delta(\mathrm{ppm})=7.19\left(\mathrm{~d},{ }^{3} \mathrm{~J}=8.7 \mathrm{~Hz}, 2 \mathrm{H}, 4\right), 6.89\left(\mathrm{~d},{ }^{3} \mathrm{~J}=8.7 \mathrm{~Hz}, 2 \mathrm{H}, 5\right)$, $3.90(\mathrm{~s}, 4 \mathrm{H}, 8), 2.96(\mathrm{~s}, 6 \mathrm{H}, 9)$.

${ }^{13} \mathrm{C}$ NMR $\left(176 \mathrm{MHz}, \mathrm{DMSO}-\mathrm{d}_{6}, \mathrm{RT}\right): \delta(\mathrm{ppm})=166.35(1 \mathrm{C}, 2), 148.35(1 \mathrm{C}, 7), 130.01(1 \mathrm{C}, 3), 124.03(2 \mathrm{C}$, 4), 118.03 (2C, 5), 107.79 (1C, 1), 50.21 (1C, 6), 35.45 (2C, 8), 32.95 (2C, 9).

FT-IR (ATR) $\tilde{\nu}\left(\mathrm{cm}^{-1}\right): 2932(\mathrm{w}), 2171(\mathrm{~s}), 2132(\mathrm{~s}), 1595(\mathrm{~s}), 1499(\mathrm{~m}), 1370(\mathrm{~m}), 1324(\mathrm{~m}), 1297(\mathrm{~m}), 936$ $(\mathrm{m}), 827(\mathrm{~s})$.

UV/Vis (DMSO) $\lambda_{\max } \mathrm{nm}\left(\varepsilon\left[\mathrm{Lmol}^{-1} \mathrm{~cm}^{-1}\right]\right): 381$ (23500).

UV/Vis (ACN) $\lambda_{\max } \mathrm{nm}\left(\varepsilon\left[\mathrm{Lmol}^{-1} \mathrm{~cm}^{-1}\right]\right): 377$ (22800).

UV/Vis (DMF) $\lambda_{\max } \mathrm{nm}\left(\varepsilon\left[\mathrm{Lmol}^{-1} \mathrm{~cm}^{-1}\right]\right): 385$ (25000)

UV/Vis (Methanol) $\lambda_{\max } \mathrm{nm}\left(\varepsilon\left[\mathrm{Lmol}^{-1} \mathrm{~cm}^{-1}\right]\right): 368$ (23900).

UV/Vis (THF) $\lambda_{\max } \mathrm{nm}\left(\varepsilon\left[\mathrm{Lmol}^{-1} \mathrm{~cm}^{-1}\right]\right): 416(4300)$.

MS (EI): $239.12(100)[\mathrm{MH}]^{+}, 238.12(27)[\mathrm{M}]^{+}, 180.98(58), 166.02(25), 68.99(30)$.

EA*: $\mathrm{C}_{14} \mathrm{H}_{14} \mathrm{~N}_{4}$; calc.: $\mathrm{C}, 70.57 ; \mathrm{N}, 23.51 ; \mathrm{H}, 5.92$; meas.: $\mathrm{C}, 70.61 ; \mathrm{N}, 22.16 ; \mathrm{H}, 6.021$.

*Small amounts of acetonitrile and water may be responsible for the deviations of calculated and measured values.

\subsection{2 -(4-(1,3-dihydro-2 $H$-benzo[ $d$ ] ]imidazol-2-ylidene)cyclohexa-2,5-dien-1- ylidene)malononitrile (2)}

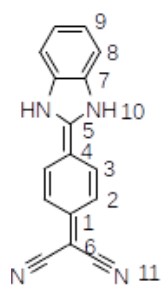

\begin{abstract}
Under argon atmosphere, ortho-Phenylendiamine $(70.0 \mathrm{mg}, 0.64 \mathrm{mmol}, 1 \mathrm{eq}$.$) , dissolved in$ acetonitrile $(15 \mathrm{~mL})$, was added to a $40^{\circ} \mathrm{C}$ warm solution of PTCNQ $(160.0 \mathrm{mg}, 0.64 \mathrm{mmol}$, 1 eq.) in acetonitrile $(20 \mathrm{~mL})$. The solution turned red after 20 hours at $70^{\circ}$. After cooling to room temperature, the solution stood for 4 days in the fridge. Filtration then yielded a fine grain greenish powder which was washed with cooled acetonitrile $(3 \times 5 \mathrm{~mL})$. The product was recrystallized from acetonitrile to yield fine yellow crystals $(70.2 \mathrm{mg}, 0.27 \mathrm{mmol}$, $43 \%)$.
\end{abstract}

${ }^{1} \mathbf{H}$ NMR $(700 \mathrm{MHz}$, DMSO-d $6, \mathrm{RT}): \delta(\mathrm{ppm})=14.35$ (bs, $\left.2 \mathrm{H}, 10\right), 7.86\left(\mathrm{~d},{ }^{3} \mathrm{~J}=8.7 \mathrm{~Hz}, 2 \mathrm{H}, 2\right), 7.69\left(\mathrm{q},{ }^{3} \mathrm{~J}\right.$ $=8.7 \mathrm{~Hz}, 2 \mathrm{H}, 9), 7.47\left(\mathrm{q},{ }^{3} \mathrm{~J}=8.6 \mathrm{~Hz}, 2 \mathrm{H}, 8\right), 6.95\left(\mathrm{~d},{ }^{3} \mathrm{~J}=8.7 \mathrm{~Hz}, 2 \mathrm{H}, 3\right)$.

${ }^{13} \mathrm{C}$ NMR $(176 \mathrm{MHz}$, DMSO-d $6, \mathrm{RT}): \delta(\mathrm{ppm})=150.27(1 \mathrm{C}, 6), 149.31(1 \mathrm{C}, 5), 132.26(1 \mathrm{C}, 1), 128.54,126.54$ (1C, 2), $125.48(2 \mathrm{C}, 8), 123.51(2 \mathrm{C}, 7), 118.49(2 \mathrm{C}, 3), 113.47(2 \mathrm{C}, 9), 79.63(1 \mathrm{C}, 4)$.

FT-IR (ATR) $\tilde{\nu}\left(\mathrm{cm}^{-1}\right): 2952(\mathrm{w}), 2877(\mathrm{w}), 2849(\mathrm{w}), 2761(\mathrm{w}), 2190(\mathrm{~s}), 2140(\mathrm{~s}), 1637(\mathrm{w}), 1612(\mathrm{~m}), 1503$ $(\mathrm{m}), 1459(\mathrm{~m}), 1387(\mathrm{~m}), 1336(\mathrm{~m}), 1230(\mathrm{~m}), 1201(\mathrm{~m}), 819(\mathrm{~s}), 742(\mathrm{~s})$.

UV/Vis (DMSO) $\lambda_{\max } \mathrm{nm}\left(\varepsilon\left[\mathrm{Lmol}^{-1} \mathrm{~cm}^{-1}\right]\right): 392(42200)$.

UV/Vis $(A C N) \lambda_{\max } \mathrm{nm}\left(\varepsilon\left[\mathrm{Lmol}^{-1} \mathrm{~cm}^{-1}\right]\right): 385$ (86800). 
UV/Vis (DMF) $\lambda_{\max } \mathrm{nm}\left(\varepsilon\left[\mathrm{Lmol}^{-1} \mathrm{~cm}^{-1}\right]\right): 391(56500)$

UV/Vis (Methanol) $\lambda_{\max } \mathrm{nm}\left(\varepsilon\left[\mathrm{Lmol}^{-1} \mathrm{~cm}^{-1}\right]\right): 424$ (20000).

UV/Vis (THF) $\lambda_{\max } \mathrm{nm}\left(\varepsilon\left[\mathrm{Lmol}^{-1} \mathrm{~cm}^{-1}\right]\right): 388(7000)$.

MS (EI): $\mathrm{m} / \mathrm{z}=259.10$ (15), $258.09[\mathrm{MH}]{ }^{+}(100), 257.10$ (5), 232 (5)

EA: $\mathrm{C}_{16} \mathrm{H}_{10} \mathrm{~N}_{4}$; calc.: $\mathrm{C}, 74.40 ; \mathrm{N}, 21.69 ; \mathrm{H}, 3.90$; meas.: $\mathrm{C}, 74.31 ; \mathrm{N}, 21.78 ; \mathrm{H}, 4.07$.

\title{
2.5 2-(4-(1-Methyl-1,3-dihydro-2H-benzo[d]imidazol-2-yliden)cyclohexa-2,5-dien-1- yliden)malononitrile (2Me)
}

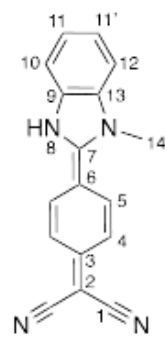

\begin{abstract}
$\mathrm{N}$-Methylphenylen-1,2-diamin $(147 \mathrm{mg}, 0.137 \mathrm{~mL}, 1.21 \mathrm{mmol}, 1$ eq. $)$ was added to a $40{ }^{\circ} \mathrm{C}$ warm solution of PTCNQ (300 mg, $1.21 \mathrm{mmol}, 1$ eq.) in acetonitrile. The solution was stirred at $70{ }^{\circ} \mathrm{C}$ for 24 hours and then cooled to room temperature. The precipitate was filtered off and washed with cooled acetonitrile $(3 \times 5 \mathrm{~mL})$ to yield the product as a green powder (58 mg, $0.23 \mathrm{mmol}, 19 \%)$.
\end{abstract}

${ }^{1} \mathbf{H}$ NMR $\left(500 \mathrm{MHz}\right.$, DMSO- $\left.\mathrm{d}_{6}, \mathrm{RT}\right): \delta(\mathrm{ppm})=7.93(\mathrm{~m}, 1 \mathrm{H}, 12), 7.73(\mathrm{~m}, 1 \mathrm{H}, 10), 7.63\left(\mathrm{~d},{ }^{3} \mathrm{~J}=8.7 \mathrm{~Hz}, 2 \mathrm{H}\right.$, $11), 7.56(\mathrm{~m}, 2,5), 6.97\left(\mathrm{~d},{ }^{3} \mathrm{~J}=8.7 \mathrm{~Hz}, 2 \mathrm{H}, 4\right), 4.03(\mathrm{~s}, 3 \mathrm{H}, 14)$.

${ }^{13} \mathrm{C}$ NMR $\left(176 \mathrm{MHz}, \mathrm{DMSO}-\mathrm{d}_{6}, \mathrm{RT}\right): \delta(\mathrm{ppm})=151.32(1 \mathrm{C}, 2), 148.65(1 \mathrm{C}, 7), 133.97(1 \mathrm{C}, 3), 130.70(2 \mathrm{C}$, 5), $126.31(1 \mathrm{C}, 13), 125.61(2 \mathrm{C}, 11), 123.77(1 \mathrm{C}, 9), 118.34$ (2C, 4), 113.85 (1C, 10), 113.11 (1C, 12), 109.17 (2C, 1), $34.04(1 \mathrm{C}, 6), 33.49(1 \mathrm{C}, 14)$.

FT-IR (ATR) $\tilde{\nu}\left(\mathrm{cm}^{-1}\right): 3045(\mathrm{w}), 2931$ (w), 2875 (w), 2172 (s), 2127 (s), 1591 (s), 1566 (s), 1512 (m), 1494 (m), 1385 (s), 1319 (s), $1188(\mathrm{~s}), 821(\mathrm{~s}), 738$ (s).

UV/Vis (DMSO) $\lambda_{\max } \mathrm{nm}\left(\varepsilon\left[\mathrm{Lmol}^{-1} \mathrm{~cm}^{-1}\right]\right): 373$ (19750).

UV/Vis (ACN) $\lambda_{\max } \mathrm{nm}\left(\varepsilon\left[\mathrm{Lmol}^{-1} \mathrm{~cm}^{-1}\right]\right): 368(7350)$.

UV/Vis (DMF) $\lambda_{\max } \mathrm{nm}\left(\varepsilon\left[\mathrm{Lmol}^{-1} \mathrm{~cm}^{-1}\right]\right): 374(32700)$

UV/Vis (Methanol) $\lambda_{\max } \mathrm{nm}\left(\varepsilon\left[\mathrm{Lmol}^{-1} \mathrm{~cm}^{-1}\right]\right): 375$ (12200).

UV/Vis (THF) $\lambda_{\max } \mathrm{nm}\left(\varepsilon\left[\mathrm{Lmol}^{-1} \mathrm{~cm}^{-1}\right]\right): 303$ (5650).

MS (EI): $\mathrm{m} / \mathrm{z}=273.11(12)[\mathrm{M}]^{+}, 272.10(70)[\mathrm{M}]^{+}, 271.10(100)[\mathrm{M}], 149.06(25)$.

EA*: $\mathrm{C}_{17} \mathrm{H}_{12} \mathrm{~N}_{4}$; calc.: $\mathrm{C}, 74.98 ; \mathrm{N}, 20.58 ; \mathrm{H}, 4.44$; meas.: $\mathrm{C}, 71.68 ; \mathrm{N}, 20.58 ; \mathrm{H}, 5.486$.

*Small amounts of acetonitrile and water may be responsible for the deviations of calculated and measured values.

\subsection{2 -(4-(1,3-Dimethyl-1,3-dihydro-2 $H$-benzo[ $d$ ]imidazol-2-yliden)cyclohexa-2,5-dien- 1-yliden)malononitrile $\left(2 \mathrm{Me}_{2}\right)$}<smiles>CN1C(=c2ccc(=C(C#N)C#N)cc2)N(C)c2ccccc21</smiles>

$N, N$ '-Dimethyl-1,2-phenylendiamine (54 mg, $43.5 \mu \mathrm{L}, 0.4 \mathrm{mmol}, 1 \mathrm{eq}$.) was added to a $40{ }^{\circ} \mathrm{C}$ warm solution of PTCNQ (300 mg, $1.21 \mathrm{mmol}, 1$ eq.) in acetonitrile. The solution was stirred at $70{ }^{\circ} \mathrm{C}$ for 20 hours and then cooled to room temperature. The precipitate was filtered off and washed with cooled acetonitrile $(3 \times 5 \mathrm{~mL})$ to yield the product as a green powder (28.3 $\mathrm{mg}, 0.10 \mathrm{mmol}, 25 \%)$.

${ }^{1} \mathbf{H}$ NMR $(700 \mathrm{MHz}$, DMSO-d 6 , RT): $\delta(\mathrm{ppm})=8.01(\mathrm{dd}, \mathrm{J}=6.0,3.0 \mathrm{~Hz}, 2 \mathrm{H}, 11), 7.67(\mathrm{dd}, \mathrm{J}=6.0,2.9 \mathrm{~Hz}$, $2 \mathrm{H}, 10), 7.49(\mathrm{~d}, \mathrm{~J}=8.5 \mathrm{~Hz}, 2 \mathrm{H}, 5), 6.98(\mathrm{~d}, \mathrm{~J}=8.2 \mathrm{~Hz}, 2 \mathrm{H}, 4), 3.92(\mathrm{~s}, 6 \mathrm{H}, 8)$.

${ }^{13} \mathrm{C}$ NMR $\left(176 \mathrm{MHz}, \mathrm{DMSO}-\mathrm{d}_{6}, \mathrm{RT}\right): \delta(\mathrm{ppm})=151.54(1 \mathrm{C}, 2), 147.79(1 \mathrm{C}, 7), 131.82(1 \mathrm{C}, 3), 131.00(2 \mathrm{C}$, 5), $126.04(2 \mathrm{C}, 9), 123.46(2 \mathrm{C}, 11), 117.68(2 \mathrm{C}, 4), 112.90$ (1C, 10), $109.51(2 \mathrm{C}, 1), 106.52(2 \mathrm{C}, 6), 32.92(2 \mathrm{C}$, 8).

FT-IR (ATR) $\tilde{\nu}\left(\mathrm{cm}^{-1}\right): 2166(\mathrm{~s}), 2124(\mathrm{~s}), 1598(\mathrm{~s}), 1552(\mathrm{~m}), 1508(\mathrm{~m}), 1471(\mathrm{~s}), 1422(\mathrm{~m}), 1320$ (s), 1195 (s), $1231(\mathrm{~m}), 1164(\mathrm{~m}), 1028(\mathrm{~m}), 828(\mathrm{~s}), 810(\mathrm{~m}), 737(\mathrm{~s})$.

UV/Vis (DMSO) $\lambda_{\max } \mathrm{nm}\left(\varepsilon\left[\mathrm{Lmol}^{-1} \mathrm{~cm}^{-1}\right]\right): 410$ (20950).

UV/Vis $(A C N) \lambda_{\max } \mathrm{nm}\left(\varepsilon\left[\mathrm{Lmol}^{-1} \mathrm{~cm}^{-1}\right]\right): 409$ (22200).

UV/Vis (DMF) $\lambda_{\max } \mathrm{nm}\left(\varepsilon\left[\mathrm{Lmol}^{-1} \mathrm{~cm}^{-1}\right]\right): 415$ (24100). 
UV/Vis (Methanol) $\lambda_{\max } \mathrm{nm}\left(\varepsilon\left[\mathrm{Lmol}^{-1} \mathrm{~cm}^{-1}\right]\right): 396$ (16500).

UV/Vis (THF) $\lambda_{\max } \mathrm{nm}\left(\varepsilon\left[\mathrm{Lmol}^{-1} \mathrm{~cm}^{-1}\right]\right): 454$ (11600).

MS (ESI): $\mathrm{m} / \mathrm{z}=881.34(23)[3 \mathrm{M}-\mathrm{Na}]^{+}, 611.20(26)[2 \mathrm{M}-\mathrm{K}]^{+}, 595.22(55)[2 \mathrm{M}-\mathrm{Na}]^{+}, 325.08(90)[\mathrm{M}-\mathrm{K}]^{+}$, $309.10(100)[\mathrm{M}-\mathrm{Na}]^{+}, 287.12(55)[\mathrm{MH}]^{+}$.

EA*: $\mathrm{C}_{18} \mathrm{H}_{14} \mathrm{~N}_{4} ; \mathrm{C}, 75.50 ; \mathrm{N}, 19.57 ; \mathrm{H}, 4.93$; meas.: C, 71.13; N, 17.76; H, 5.11.

*Small amounts of acetonitrile and water may be responsible for the deviations of calculated and measured values. 


\section{$3 \mathrm{UV} / \mathrm{Vis}$ titration experiments}

Table S1: Fluorescence quantum yields (QY) in \% and excited state lifetimes $(\tau)$ in ns of all compounds in solvents of increasing polarity as determined by the normalized Dimroth-Reichardt Parameter $\mathrm{E}_{\mathrm{T}}^{\mathrm{N}}{ }^{\left[{ }^{[2]}\right.}$ Notably large quantum yields are highlighted in bold blue.

\begin{tabular}{|c|c|c|c|c|c|c|c|c|c|c|c|c|c|}
\hline & & \multicolumn{2}{|c|}{$1^{*}$} & \multicolumn{2}{|c|}{$1 \mathrm{Me}^{*}$} & \multicolumn{2}{|c|}{$1 \mathrm{Me}_{2}$} & \multicolumn{2}{|c|}{$2^{*}$} & \multicolumn{2}{|c|}{$2 \mathrm{Me}$} & \multicolumn{2}{|c|}{$2 \mathrm{Me}_{2}$} \\
\hline $\mathrm{E}_{\mathrm{T}}^{\mathrm{N}}$ & solvent & QY & $\tau$ & QY & $\tau$ & QY & $\tau$ & QY & $\tau$ & QY & $\tau$ & QY & $\tau$ \\
\hline 0.207 & THF & 7 & $<0.2$ & $<1$ & 0.3 & $<1$ & 0.3 & 73 & 2.4 & 3 & 1.6 & $<1$ & $<0.2$ \\
\hline 0.386 & DMF & 7 & 2.1 & 4 & 2.1 & 3 & 2.77 & 72 & 1.8 & 90 & 2.1 & 3 & 0.5 \\
\hline 0.444 & DMSO & 10 & 0.8 & $<1$ & 1.1 & $<1$ & 1.4 & 92 & 1.8 & 4 & 1.8 & $<1$ & 0.5 \\
\hline 0.460 & $\mathrm{ACN}$ & 7 & $<0.2$ & $<1$ & 0.5 & $<1$ & $<0.2$ & 71 & 6.3 & 79 & 2.2 & $<1$ & 1.1 \\
\hline 0.762 & $\mathrm{MeOH}$ & $<1$ & $<0.2$ & $<1$ & $<0.2$ & $<1$ & $<0.2$ & 35 & 0.4 & 16 & 0.5 & $<1$ & $<0.2$ \\
\hline
\end{tabular}

${ }^{*} \mathrm{QY}$ of $\mathbf{1}, \mathbf{1 M e}$, and 2 were taken from ref. ${ }^{[1]}$ 

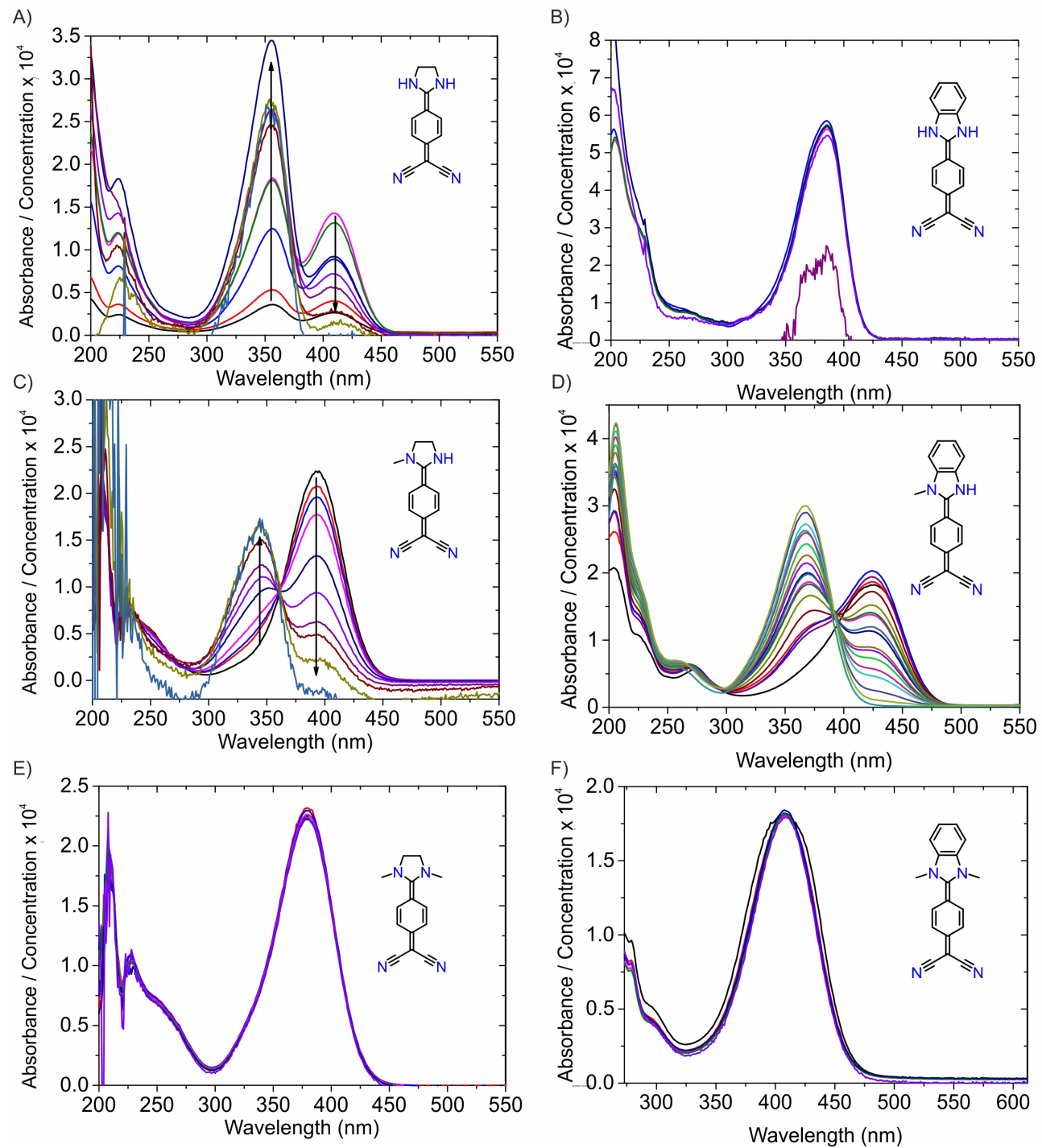

Figure S1: Wavelength-dependence of the concentration-normalized absorbance (absorbance spectra divided by dye concentration) of all compounds in acetonitrile. Concentrations range from $1 \times 10^{-4} \mathrm{M}$ to $5 \times 10^{-6} \mathrm{M}$, in case of 2 (B) to $5 \times 10^{-8} \mathrm{M}$ (purple graph). 
A)

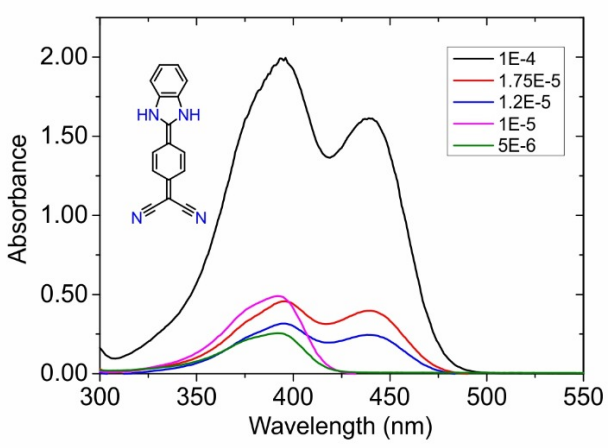

B)

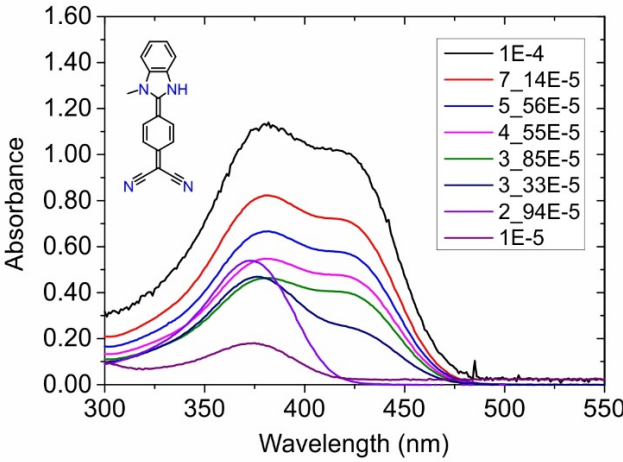

C)

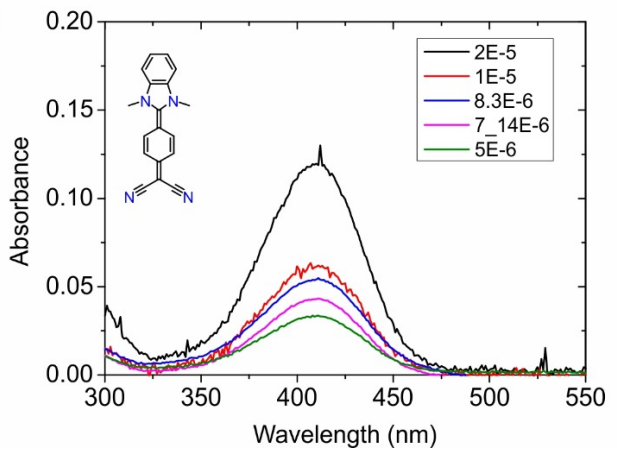

D)
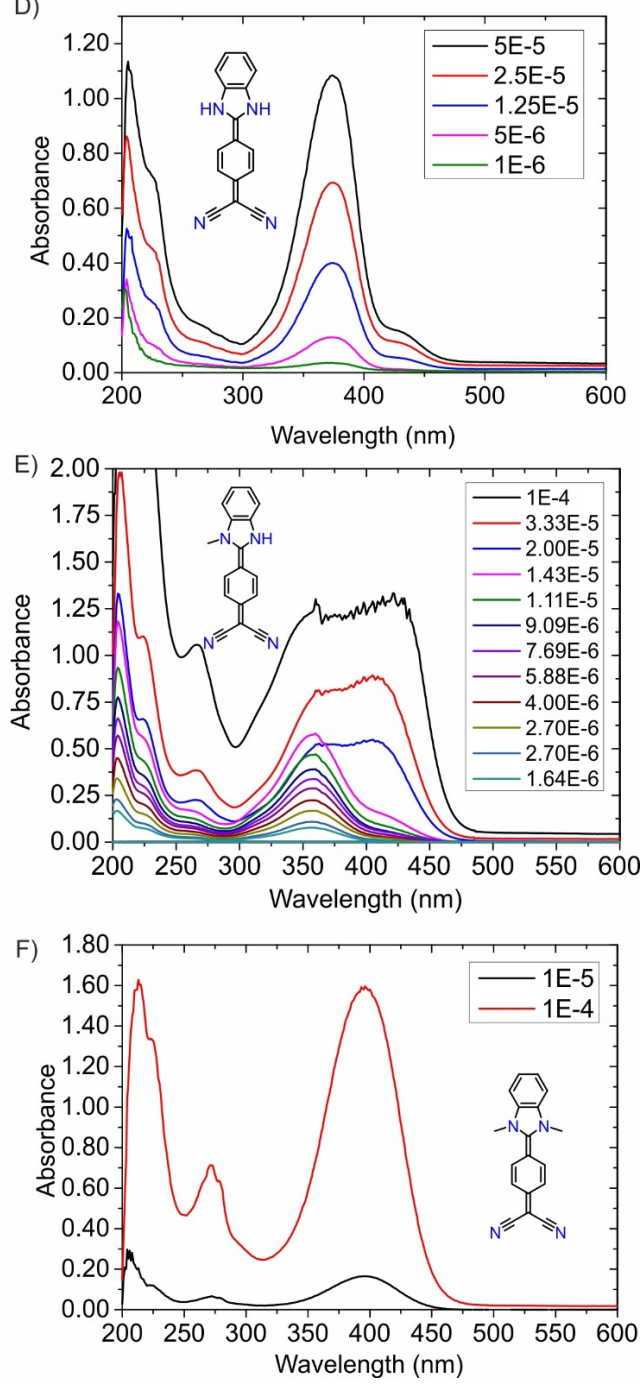

Figure S2: Absorption spectra of $2,2 \mathrm{Me}$, and $2 \mathrm{Me}_{2}$ in $\mathrm{DMSO}(\mathrm{A}-\mathrm{C})$ and $\mathrm{MeOH}(\mathrm{D}-\mathrm{F})$ at different concentrations. Concentrations are given in the insets. 


\subsection{Temperature dependence}
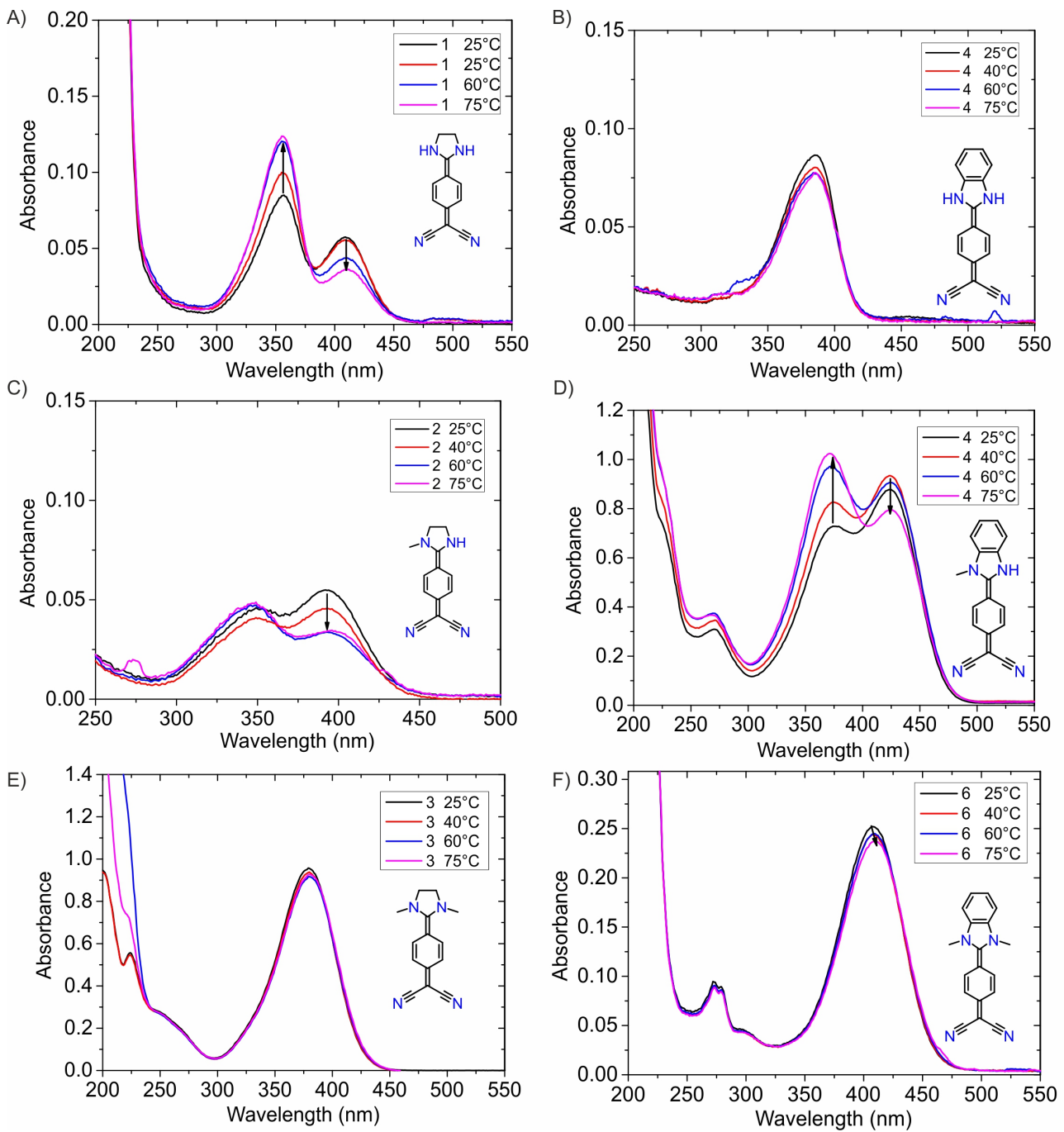

Figure S3: Temperature dependent absorption measurements of all compounds in solutions of acetonitrile with concentrations of $1 \times 10^{-5} \mathrm{M}$. Temperatures are given in the insets. 


\subsection{Effect of polar additives}
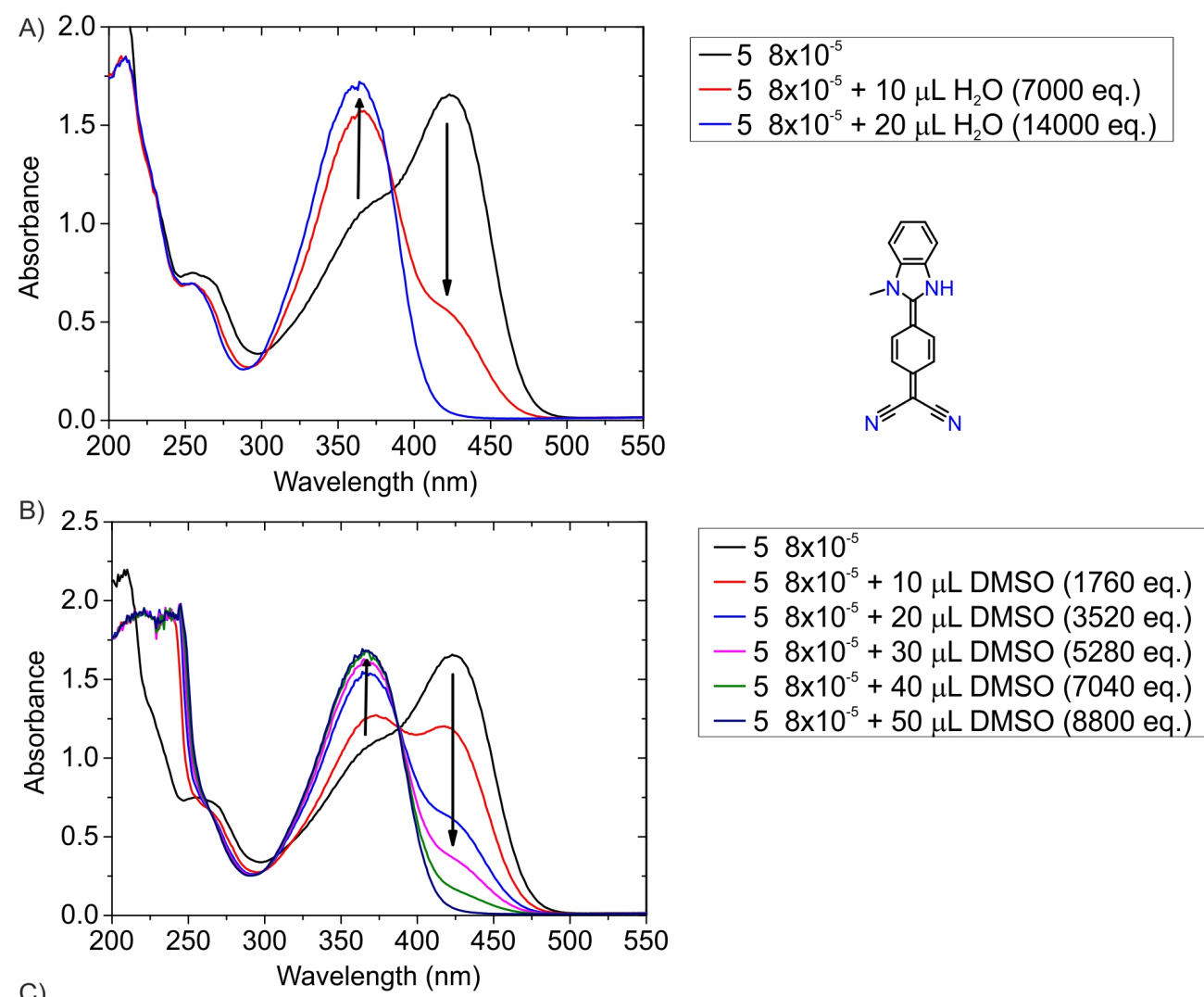

C)

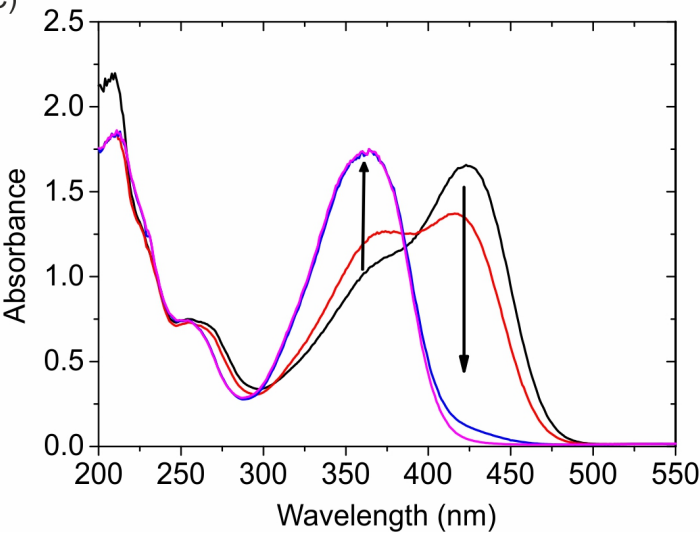

$$
\begin{array}{rl}
-5 & 8 \times 10^{-5} \\
-5 & 8 \times 10^{-5}+10 \mu \mathrm{L} \mathrm{NaOH} \\
-5 & 8 \times 10^{-5}+20 \mu \mathrm{L} \mathrm{NaOH} \\
-5 & 8 \times 10^{-5}+30 \mu \mathrm{L} \mathrm{NaOH}
\end{array}
$$

Figure S4: Absorption spectra of $2 \mathrm{Me}$ in $\mathrm{ACN}$ with a starting concentration of $8 \times 10^{-5} \mathrm{M}$ and increasing amounts of (polar) additives: A) $\mathrm{H}_{2} \mathrm{O}$. B) DMSO. C) Aqueous $\mathrm{NaOH}\left(1 \times 10^{-4} \mathrm{M}\right)$. Equivalents are given with respect to solute concentration. 


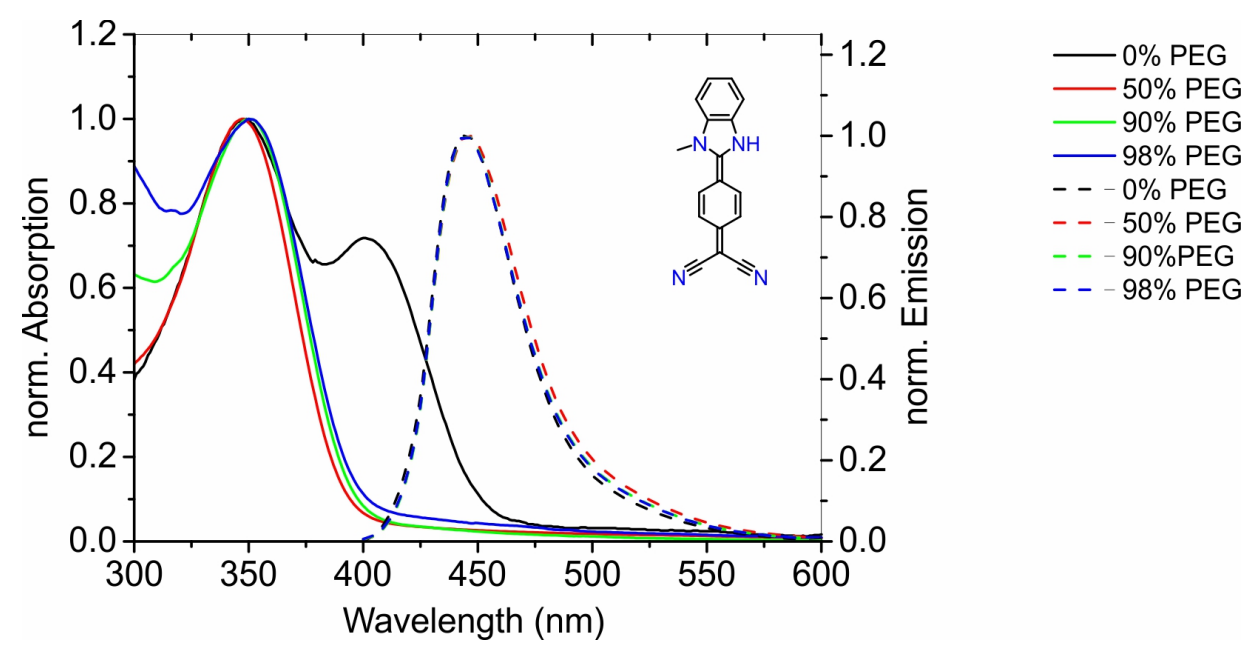

Figure S5: Normalized absorption (solid) and normalized emission (dashed) spectra (excitation at $366 \mathrm{~nm}$ ) of $2 \mathrm{Me}$ in pure acetonitrile (black) and mixtures of acetonitrile with polyethylenglycol: $50 \%$ PEG (red), $90 \%$ (green) and $98 \%$ (blue). While the red-shifted absorption band disappears, the emission spectra are unaffected by the addition of PEG. The change in the absorption spectra is accompanied by a change in colour as observed in Fig. 1 in the main text.

Table S2: Measured densities $\rho$ and dynamic viscosities $\eta$ of the ACN/PEG mixture

\begin{tabular}{ccc} 
ACN $/$ PEG & $\rho\left(20{ }^{\circ} \mathrm{C}\right)\left[\mathrm{g} \mathrm{m} \mathrm{L}^{-1}\right]$ & $\eta[\mathrm{m} \mathrm{Pa} \mathrm{s}]$ \\
\hline $100 / 0$ & 0.7843 & 0.3720 \\
$50 / 50$ & 0.9710 & 4.1152 \\
$10 / 90$ & 1.0966 & 54.3671 \\
$2 / 98$ & 1.1153 & 99.9220 \\
\hline
\end{tabular}

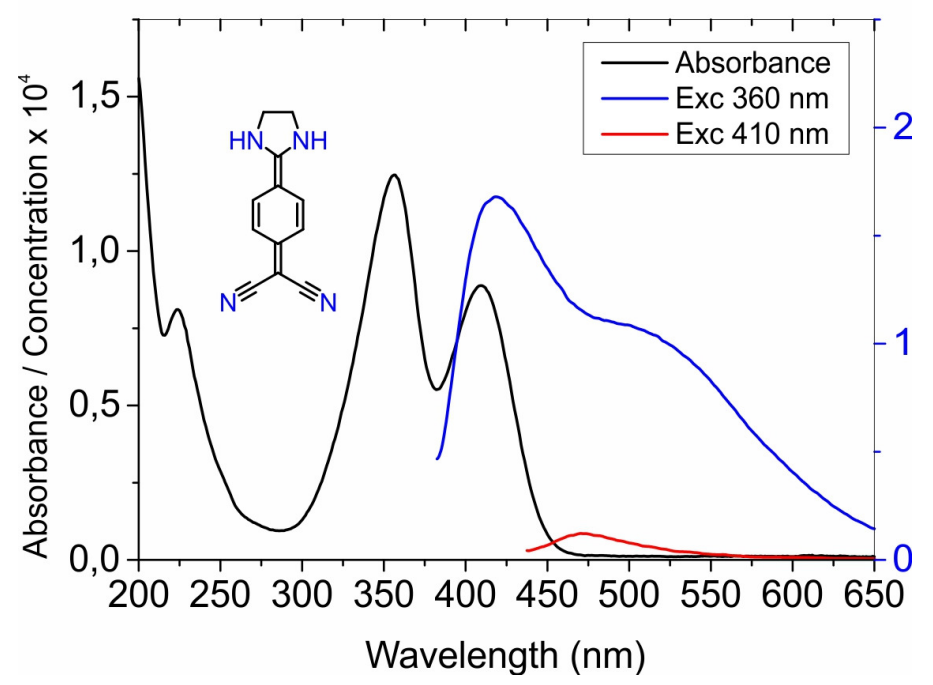

Figure S6: Absorption spectra of compound 1 in $\mathrm{ACN}$ at a concentration of $2 \cdot 10^{-5} \mathrm{M}$ (black line) and emission spectra recorded after exicitation at $360 \mathrm{~nm}$ (blue line) and $410 \mathrm{~nm}$ (red line). The emission after excitation at $410 \mathrm{~nm}$, i.e., the red-shifted absorption band, is negligibly low compared to the emission after excitation of the blue shifted absorption band $(360 \mathrm{~nm})$. 


\section{Excitation emission matrices}
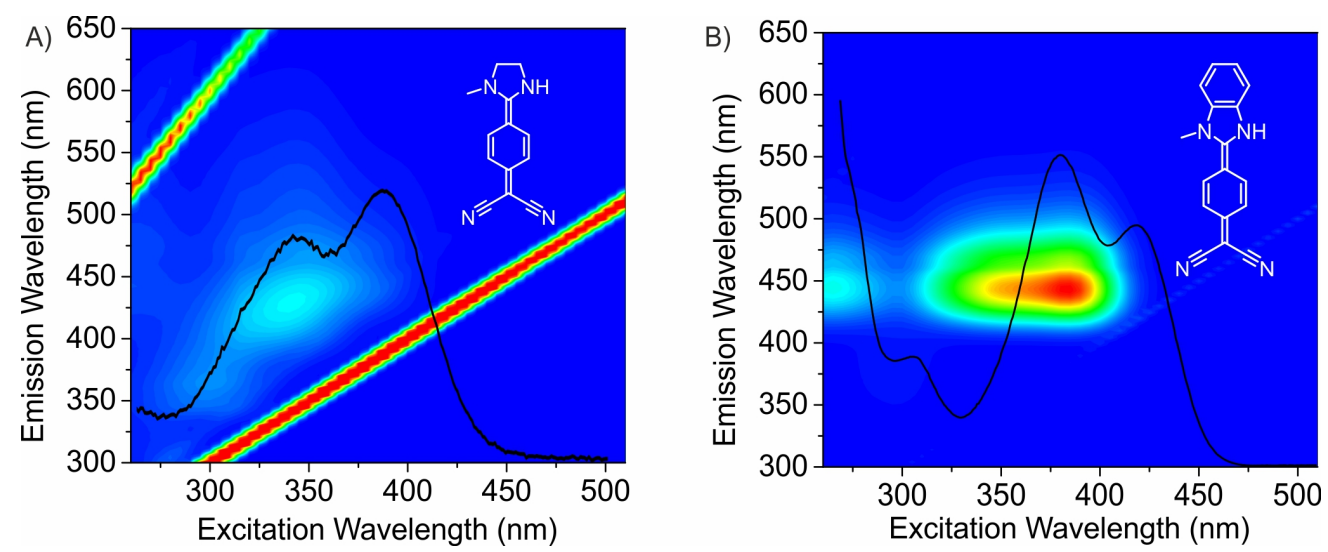

Figure S7: Excitation emission matrices (EEM) of $1 \mathrm{Me}$ and $2 \mathrm{Me}$ in $\mathrm{ACN}$. The overlayed black spectra are the respective absorption spectra at the same concentration A) $5 \times 10^{-6} \mathrm{M}$ and B) $2 \times 10^{-5} \mathrm{M}$.
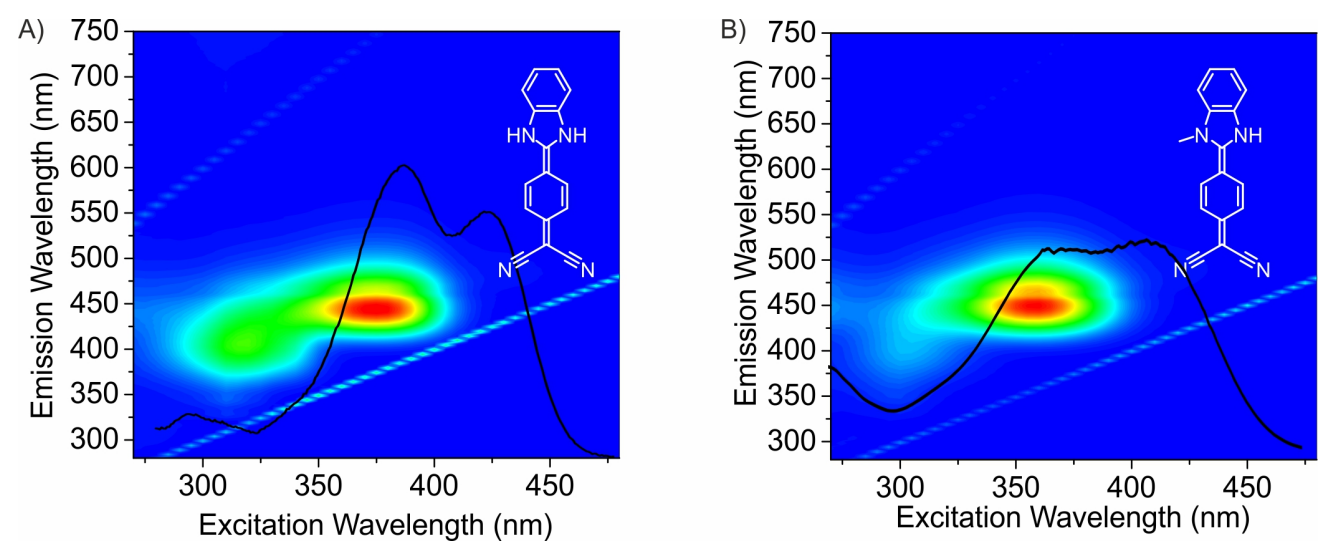

Figure S8: Excitation emission matrices (EEM) of 2 and $2 \mathrm{Me}$ in methanol. The overlayed black spectra are the respective absorption spectra at the same concentration A) $5 \times 10^{-6} \mathrm{M}$ and B) $2 \times 10^{-5} \mathrm{M}$. 


\section{Computational Details}

The conformational landscape of DADQ aggregates was investigated by metadynamics simulations based on the GFN2-xTB method and CREST. ${ }^{[3,4]}$ The dimers shown in Figure 2 of the main text and all other oligomers displayed further down below were chosen after visual inspection. All structure optimizations were performed using the Turbomole program package ${ }^{[5]}$ employing the PBEh-3 ${ }^{[6]}$ composite method in combination with the $\mathrm{COSMO}^{[7]}$ solvent model. Stationary points were confirmed to be minima on the PES by normal mode analyses showing no imaginary frequencies. Vacuum single point electronic energies $E$ were calculated at the $\omega \mathrm{B} 97 \mathrm{X}$ D3/def2-QZVP ${ }^{[8-10]}$ level of DFT utilizing the ORCA program package (version 4.2.0). ${ }^{[11]}$ Solvation effects $\delta G_{\text {solv }}$ were estimated within the COSMO-RS ${ }^{[12]}$ framework with the COSMOtherm program suite ${ }^{[13]}$ using its BP_TZVPD_FINE_19 parametrization. Free association enthalpies were computed according to

$$
\Delta G_{\mathrm{a}}=\Delta E+\Delta H_{\mathrm{vib}}-T \Delta S_{\mathrm{vib}}^{\mathrm{RRHO}}+\Delta \delta G_{\mathrm{solv}} .
$$

$\Delta H_{\mathrm{vib}}$ and $\Delta S_{\mathrm{vib}}^{\mathrm{RROO}}$ are extracted from normal mode analyses using, in addition, Grimme's rigid-rotor harmonicoscillator (RRHO) correction to account for the anharmonicity of low-lying frequencies that often lead to inaccuracies in the calculation of binding energies, ${ }^{[14]} \Delta \delta G_{\text {solv }}$ additionally contains a correction $\Delta G_{\text {conc }}$ of $+7.92 \mathrm{~kJ} / \mathrm{mol}$ taking into account the $1 \mathrm{M}$ reference concentration in solution. ${ }^{[15]} \mathrm{A}$ lower-level combination of Grimme's semiempirical GFN2-xTB program for optimizations and normal mode analyses and $\omega$ B97X-D3/def2-TZVP single point calculations was employed for higher aggregates up to hexamers.

The ground-state PES of $\mathbf{1}$ (Figure 6 in the main text) was scanned at the SMD/ $\omega$ B97X-D3/def2-TZVP level by fixing the carbon atoms between the amino groups and cyano moities at every step to their cartesian position and optimizing every other coordinate of the dimer at a fixed intermolecular distance of $3.56 \AA$. Transition state searches were performed with Turbomole's woelfling module. Metastable dimer species were optimized with a much shorter displacement step $(d q \max =0.005)$ than all other structures $(d q \max =0.05)$. Electronic energies to estimate transition state barriers were computed at the $\omega$ B97X-D3/def2-QZVP level using the SMD ${ }^{[16]}$ solvent model with $\varepsilon=37.5^{[17]}$ for ACN since the COSMO-RS approach is much better suited for comparing relative energies of conformers rather than estimating transition state barriers. ${ }^{[18]}$

FMO-EDA ${ }^{[19,20]}$ calculations were performed at the $\omega$ B97X-D3(BJ)/def2-TZVP level ( $w B 97 X-D$ and idcver=3 keywords) with the GAMESS program package. ${ }^{[21]}$ Note that due to differences in implementation, the dispersive correction used for energies and EDA calculations is not the same, but should yield comparable results. We refer to the respective program manuals for details.

To obtain insight into the photochemical behavior of DADQ aggregates, we employed the DFT/MRCI [22] approach, which is particularly useful for the treatment of molecular aggregates and especially our DADQs, as single-reference TD-DFT calculations may yield unreliable results due to the inadequate description of double excitations. ${ }^{[23]}$ However, as we do not intend to base our results solely on a single method, we have additionally employed TD-DFT calculations to support the DFT/MRCI results.

Excited states were computed at the SMD/BHLYP/MRCl/def2-TZVP(-f $)^{[16,22,24]}$ level using the stand-alone DFT/MRCI program ${ }^{[25]}$ interfaced with ORCA employing the R2016 Hamiltonian and $\varepsilon=37.5$ and 46.8 for ACN and DMSO, respectively. ${ }^{[17]} \mathrm{A}$ reference space of 16 electrons and 14 orbitals with a default cut-off of 1.0 Hartree, which was carefully checked to not cut between degenerate orbitals, was chosen and all single and double excitations were incorporated. The reference space was refined once, i.e., two DFT/MRCl calculations were performed in succession. Initial testing found that a second refinement of the reference space did not yield any significant change in excitation energies, oscillator strengths, or transition dipole moments. Excited state PES scans (e.g., Figure 6 in the main text) were conducted with the smaller def2-SVP basis set. All of these excited state calculations, including the PES scans, were repeated at the $\omega$ B97X-D3/def2-TZVP level of TD-DFT to support the $\mathrm{DFT} / \mathrm{MRCl}$ results. Furthermore, trimer and tetramer conformations were computed at the $\omega$ B97X-D3/def2-SVP level of TD-DFT to assess whether they may be responsible for the red-shifted absorption band (Table S15).

To study fluorescence quencing, an excited-state optimization of a ground-state optimized displaced $(d=4.8 \AA)$ metastable dimer was performed at the IEFPCM/ $\omega$ B97XD/def2-SVP ${ }^{[26,27]}$ level of TD-DFT using the statespecific approach ${ }^{[28]}$ of the Gaussian (Version 16) program package. ${ }^{[29]}$ 


\section{Additional DADQ aggregation properties}

Table S3: Free enthalpies of association in $\mathrm{kJ} / \mathrm{mol}$ for the formation of a dimer conformation from two monomers in DMSO at $298.15 \mathrm{~K}$.

\begin{tabular}{cccccc} 
& $\mathrm{A}_{\mathrm{HB}}$ & $\mathrm{A}_{\mathrm{ST}}$ & $\mathrm{A}_{\mathrm{SD}}$ & $\mathrm{S}_{\mathrm{HT}}$ & $\mathrm{S}_{\mathrm{ST}}$ \\
\hline $\mathbf{1}$ & +0.5 & -8.0 & +14.1 & +35.3 & +50.5 \\
$\mathbf{1 M e}$ & +5.7 & +0.3 & +13.9 & +23.8 & +60.3 \\
$\mathbf{1} \mathbf{M e}_{2}$ & +16.0 & - & +8.0 & - & - \\
$\mathbf{2}$ & +2.7 & -4.1 & +1.4 & +18.2 & +34.8 \\
$\mathbf{2 M e}$ & +3.9 & +31.2 & +18.8 & +19.1 & +48.8 \\
$\mathbf{2} \mathbf{M e}_{2}$ & +18.8 & - & +23.1 & - & - \\
\hline
\end{tabular}
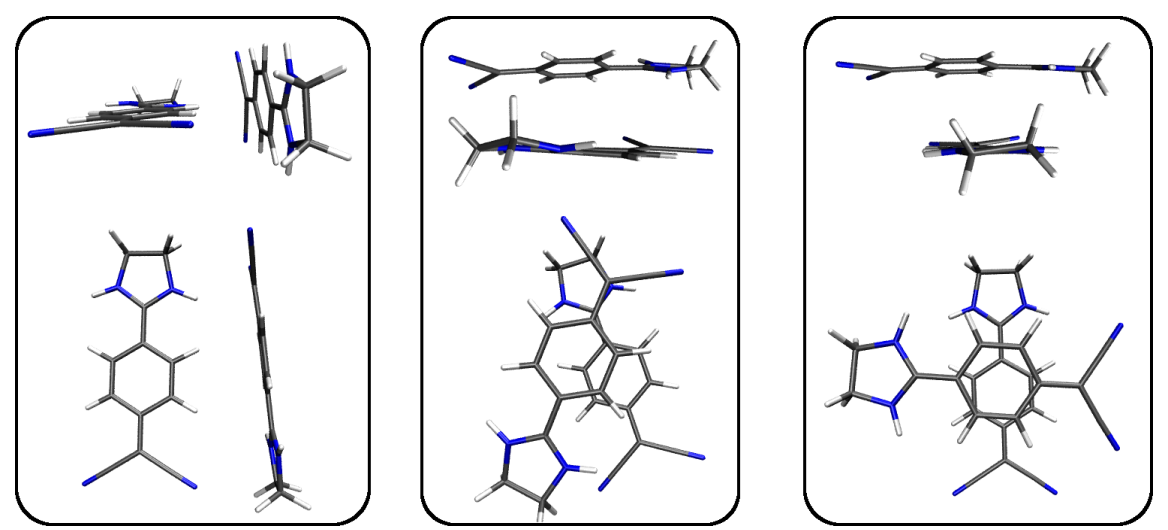

Figure S9: Other investigated dimer conformations of $\mathbf{1}$. Two viewpoints (top and side) are shown. These conformations did not provoke any interest as they were either too high in free enthalpy (middle, right) or are simply intermediates between other conformations (left).
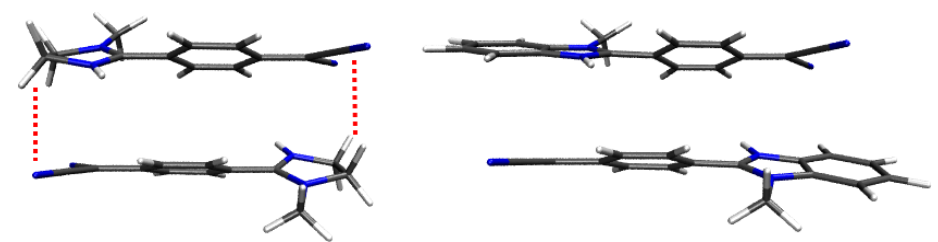

Figure S10: Side view of $\mathbf{1 M e}$ and $\mathbf{2 M e}$ to illustrate the difference in intermolecular interaction. 1 Me possesses slightly polarized terminal hydrogen atoms that may interact with the dicyano moiety in its vicinity (red dashed lines), which is not possible for $2 \mathrm{Me}$. 
Table S4: Electronic, thermal, and solvation effect contributions to $\Delta G_{\mathrm{a}}$ of all dimers in ACN normalized to a monomer and in $\mathrm{kJ} / \mathrm{mol}$

\begin{tabular}{|c|c|c|c|c|}
\hline & $\Delta E$ & $\Delta G^{\mathrm{RRHO}}$ & $\Delta G_{\text {solv }}$ & $\Delta G_{\mathrm{a}}^{\mathrm{to}}$ \\
\hline \multicolumn{5}{|c|}{1} \\
\hline$A_{H B}$ & -88.2 & 32.6 & 46.8 & -8.9 \\
\hline$A_{S T}$ & -74.5 & 30.8 & 35.5 & -8.2 \\
\hline$A_{S D}$ & -90.1 & 32.2 & 53.9 & -4.0 \\
\hline$S_{H T}$ & -23.6 & 30.1 & 4.9 & 11.4 \\
\hline $\mathrm{S}_{\mathrm{ST}}$ & -1.1 & 31.7 & -10.8 & 19.9 \\
\hline \multicolumn{5}{|c|}{$1 \mathrm{Me}$} \\
\hline$A_{H B}$ & -90.5 & 31.8 & 50.6 & -8.1 \\
\hline$A_{S T}$ & -82.6 & 30.8 & 47.8 & -3.9 \\
\hline$A_{S D}$ & -63.1 & 31.9 & 60.9 & 29.7 \\
\hline $\mathrm{S}_{\mathrm{HT}}$ & -30.1 & 30.7 & 10.0 & 10.6 \\
\hline $\mathrm{S}_{\mathrm{ST}}$ & 1.1 & 32.7 & -8.1 & 25.7 \\
\hline \multicolumn{5}{|c|}{$1 \mathrm{Me}_{2}$} \\
\hline$A_{H B}$ & -57.7 & 29.5 & 34.4 & 6.1 \\
\hline$A_{S D}$ & -80.1 & 32.7 & 49.2 & 1.8 \\
\hline \multicolumn{5}{|c|}{2} \\
\hline$A_{H B}$ & -96.6 & 35.5 & 51.0 & -10.1 \\
\hline$A_{S T}$ & -70.1 & 33.1 & 29.6 & -7.5 \\
\hline$A_{S D}$ & -87.1 & 32.0 & 52.4 & -2.6 \\
\hline $\mathrm{S}_{\mathrm{HT}}$ & -28.0 & 30.8 & 5.9 & 8.6 \\
\hline $\mathrm{S}_{\mathrm{ST}}$ & -14.3 & 33.0 & -6.7 & 12.0 \\
\hline \multicolumn{5}{|c|}{$2 \mathrm{Me}$} \\
\hline$A_{H B}$ & -100.2 & 34.8 & 54.6 & -10.8 \\
\hline$A_{S T}$ & -45.1 & 32.0 & 26.0 & 12.9 \\
\hline$A_{S D}$ & -99.4 & 32.8 & 60.9 & -5.7 \\
\hline $\mathrm{S}_{\mathrm{HT}}$ & -32.4 & 30.6 & 9.6 & 7.9 \\
\hline $\mathrm{S}_{\mathrm{ST}}$ & -14.7 & 33.9 & -0.7 & 18.5 \\
\hline \multicolumn{5}{|c|}{$2 \mathrm{Me}_{2}$} \\
\hline$A_{H B}$ & -57.4 & 32.6 & 32.1 & 7.4 \\
\hline$A_{S D}$ & -59.7 & 31.3 & 36.0 & 7.6 \\
\hline
\end{tabular}

Table S5: Electronic, thermal, and solvation effect contributions to $\Delta G_{\text {a }}$ of all dimers in DMSO normalized to a monomer and in $\mathrm{kJ} / \mathrm{mol}$

\begin{tabular}{|c|c|c|c|c|}
\hline & $\Delta E$ & $\Delta G^{\mathrm{RRHO}}$ & $\Delta G_{\mathrm{solv}}$ & $\Delta G_{\mathrm{a}}^{\mathrm{tot}}$ \\
\hline \multicolumn{5}{|c|}{1} \\
\hline$A_{H B}$ & -88.2 & 32.6 & 55.9 & 0.2 \\
\hline$A_{S T}$ & -74.5 & 30.8 & 39.7 & -4.0 \\
\hline$A_{S D}$ & -90.1 & 32.2 & 64.9 & 7.0 \\
\hline $\mathrm{S}_{\mathrm{HT}}$ & -16.7 & 30.4 & 3.9 & 17.6 \\
\hline $\mathrm{S}_{\mathrm{ST}}$ & -1.1 & 31.7 & -5.4 & 25.3 \\
\hline \multicolumn{5}{|c|}{$1 \mathrm{Me}$} \\
\hline$A_{H B}$ & -90.5 & 31.8 & 61.5 & 2.8 \\
\hline$A_{S T}$ & -82.6 & 30.8 & 51.9 & 0.1 \\
\hline$A_{S D}$ & -97.4 & 31.9 & 72.4 & 6.9 \\
\hline $\mathrm{S}_{\mathrm{HT}}$ & -30.1 & 30.7 & 20.6 & 21.1 \\
\hline $\mathrm{S}_{\mathrm{ST}}$ & 1.1 & 32.7 & -3.7 & 30.1 \\
\hline \multicolumn{5}{|c|}{$1 \mathrm{Me}_{2}$} \\
\hline$A_{H B}$ & -57.7 & 29.5 & 36.2 & 8.0 \\
\hline$A_{S D}$ & -80.1 & 32.7 & 51.4 & 4.0 \\
\hline \multicolumn{5}{|c|}{2} \\
\hline$A_{H B}$ & -96.6 & 35.5 & 62.4 & 1.4 \\
\hline$A_{S T}$ & -70.1 & 33.1 & 35.0 & -2.1 \\
\hline$A_{S D}$ & -87.1 & 32.0 & 65.3 & 10.3 \\
\hline $\mathrm{S}_{\mathrm{HT}}$ & -28.0 & 30.8 & 29.5 & 32.2 \\
\hline $\mathrm{S}_{\mathrm{ST}}$ & -14.3 & 33.0 & -1.3 & 17.4 \\
\hline \multicolumn{5}{|c|}{$2 \mathrm{Me}$} \\
\hline$A_{H B}$ & -100.2 & 34.8 & 67.3 & 1.9 \\
\hline$A_{S T}$ & -72.2 & 32.6 & 49.1 & 9.4 \\
\hline$A_{S D}$ & -99.4 & 32.8 & 74.1 & 7.5 \\
\hline $\mathrm{S}_{\mathrm{HT}}$ & -32.4 & 30.6 & 23.7 & 21.9 \\
\hline $\mathrm{S}_{\mathrm{ST}}$ & -14.7 & 33.9 & 5.2 & 24.4 \\
\hline \multicolumn{5}{|c|}{$2 \mathrm{Me}_{2}$} \\
\hline$A_{H B}$ & -57.4 & 32.6 & 34.1 & 9.4 \\
\hline$A_{S D}$ & -46.0 & 32.3 & 25.2 & 11.5 \\
\hline
\end{tabular}




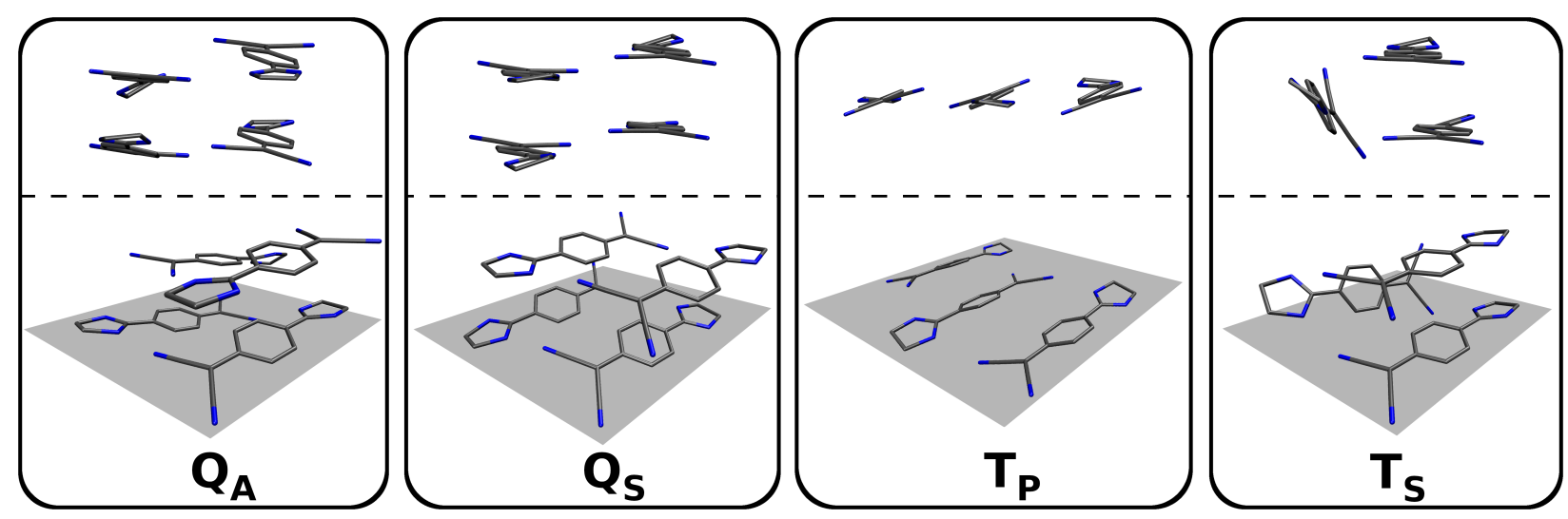

Figure S11: Selected trimer and tetramer conformations using the example of $\mathbf{1}$. Two viewpoints are used for every structure separated by a dashed line. $\mathbf{Q}_{\mathbf{A}}$ : tetramer (or quadruplex) purely consisting of anti-dimer sub-units, $\mathbf{Q}_{\mathbf{S}}$ : tetramer (or quadruplex) containing syn-dimer sub-units, $\mathbf{T}_{\mathbf{P}}$ : trimer in planar structure, $\mathbf{T}_{\mathbf{S}}$ : trimer containing a syn-dimer subunit. Hydrogen atoms are omitted for clarity. While $Q_{A}$ is always the most stable conformation, the stability of all other structures varies and depends on the DADQ compound.

\subsection{Extension to trimers and tetramers}

Apart from dimers, we have investigated DADQ trimers and tetramers, which are still somewhat feasible at an accurate level of computation. Figure S11 displays a few selected trimer and tetramer conformations of $\mathbf{1}$. Table $\mathrm{S} 6$ summarizes the relative stabilities of the most stable conformation in each aggregate up to the tetramer for all molecules.

Table S6: Normalized free enthalpies of association in $\mathrm{kJ} / \mathrm{mol}$ for the formation of the most stable conformation of a dimer (D), a trimer ( $T$ ), and a tetramer ( $Q$ - quadruplex) in ACN at $298.15 \mathrm{~K}$.

\begin{tabular}{cccc} 
& $\mathrm{D}$ & $\mathrm{T}$ & $\mathrm{Q}$ \\
\hline $\mathbf{1}$ & -8.9 & -10.1 & -19.9 \\
$\mathbf{1 M e}$ & -8.1 & -4.6 & -13.1 \\
$\mathbf{1} \mathbf{M e}_{2}$ & +1.8 & - & - \\
$\mathbf{2}$ & -10.1 & -13.0 & -24.6 \\
$\mathbf{2} \mathbf{M e}$ & -10.8 & -11.4 & -18.8 \\
$\mathbf{2} \mathbf{M e}_{2}$ & +7.4 & - & -
\end{tabular}

While there are seemingly endless possibilities to form such structures in solution, usually the tetramer $Q_{A}$ (see caption of Figure S11 for designations) is the most stable conformation for all cases even in DMSO (excluding $\mathbf{1} \mathbf{M e}_{2}$ and $\mathbf{2} \mathbf{M e}_{2}$ ). For example, the association of two $2-A_{H B}$ dimers to form $\mathbf{2}-Q_{A}$ is accompanied by a remarkable gain in free enthalpy of roughly $60 \mathrm{~kJ} / \mathrm{mol}$ in ACN. This large increase in stability is due to the local interaction of canceling dipole moments and is perhaps best illustrated using the example of $\mathbf{1}$. It is observed that $1-Q_{S}$, which is a tetramer containing two syn-dimer sub-units, is almost $40 \mathrm{~kJ} / \mathrm{mol}$ less stable than $1-Q_{A}$, which purely consists of anti-dimers (Table S7).

In contrast, stabilization of trimers is usually less pronounced in ACN and virtually non-existent in DMSO (Table S8) due to the lack of vanishing dipole moments. While 1 and $\mathbf{2}$ can be found in planar, hydrogen-bonded $\mathrm{T}_{\mathrm{P}}$ structures owing to a free unmethylated amine group, $\mathbf{1 M e}$ and $\mathbf{2 M e}$ have to resort to trimeric conformations like $T_{S}$. Electrostatic interactions in the latter are somewhat inhibited causing a third monomer to mainly interact with the other two dispersively. This is supported by an EDA calculation, which yields around $74 \%$ for the electrostatic component of the stabilising interaction in $\mathbf{1}-\mathrm{T}_{\mathrm{P}}$ and circa $57 \%$ for $\mathbf{1}-\mathrm{T}_{\mathrm{S}}$.

In general, $\mathbf{1 M e}$ and $\mathbf{2 M e}$ seem to form rather well-defined aggregates such as the dimer conformation $A_{\mathrm{HB}}$ or the tetramer conformation $Q_{A}$, while $\mathbf{1}$ and $\mathbf{2}$ may form aggregates of much greater complexity. For example, the latter two may extend the trimer conformation $T_{P}$ with a fourth molecule to form a nearly planar tetramer purely facilitated through hydrogen-bonding. Figure S12 illustrates the expansive landscape of conformations 
Table S7: Normalized free enthalpies of association in $\mathrm{kJ} / \mathrm{mol}$ for the formation of trimer $(\mathrm{T})$ and tetramer $(\mathrm{Q})$ conformations in ACN at $298.15 \mathrm{~K}$. See text for designations.

\begin{tabular}{ccccc} 
& $\mathrm{Q}_{\mathrm{A}}$ & $\mathrm{Q}_{\mathrm{S}}$ & $\mathrm{T}_{\mathrm{P}}$ & $\mathrm{T}_{\mathrm{S}}$ \\
\hline $\mathbf{1}$ & -19.9 & -10.1 & -10.1 & -6.0 \\
$\mathbf{1 M e}$ & -13.1 & - & - & -4.6 \\
$\mathbf{2}$ & -24.6 & - & -12.5 & -13.0 \\
$\mathbf{2 M e}$ & -18.8 & - & - & -11.4 \\
\hline
\end{tabular}

Table S8: Normalized free enthalpies of association in $\mathrm{kJ} / \mathrm{mol}$ for the formation of trimer $(\mathrm{T})$ and tetramer $(\mathrm{Q})$ conformations in DMSO at $298.15 \mathrm{~K}$. See text for designations.

\begin{tabular}{ccccc} 
& $\mathrm{Q}_{\mathrm{A}}$ & $\mathrm{Q}_{\mathrm{S}}$ & $\mathrm{T}_{\mathrm{P}}$ & $\mathrm{T}_{\mathrm{S}}$ \\
\hline $\mathbf{1}$ & -6.9 & +1.0 & +2.0 & +4.6 \\
$\mathbf{1 M e}$ & -1.4 & - & - & 6.8 \\
$\mathbf{2}$ & -5.8 & - & +2.6 & +0.3 \\
$\mathbf{2 M e}$ & -4.8 & - & - & +2.2 \\
\hline
\end{tabular}

from dimers to tetramers for 2 .

Less accurate, but much more time- and resource-efficient semi-empirical calculations make it possible to obtain some information about aggregates beyond tetramers (Figure S13 and Table S9). It can be observed that even pentamers and hexamers may still be stable structures. While we are confident that most of the DADQ aggregation features are well covered by our dimer analyses, the properties of higher aggregates eventually leading up to the solid state are comparably difficult to address both experimentally and theoretically and will be the subject of further investigations in the future.

Table S9: Normalized free enthalpies of association in $\mathrm{kJ} / \mathrm{mol}$ for the formation of dimers (D), trimers $(T)$, tetramers (Q), pentamers $(\mathrm{P})$, and hexamers $(\mathrm{H})$ conformations in ACN at $298.15 \mathrm{~K}$ using lower-level calculations (see computational details).

\begin{tabular}{cccccc} 
& $\mathrm{D}$ & $\mathrm{T}$ & $\mathrm{Q}$ & $\mathrm{P}$ & $\mathrm{H}$ \\
\hline $\mathbf{1}$ & -7.0 & -7.7 & -11.1 & -12.6 & -12.2 \\
$\mathbf{1 M e}$ & -4.1 & -1.6 & -12.7 & -6.2 & -10.1 \\
$\mathbf{1} \mathbf{M e}_{2}$ & -1.4 & +4.2 & +17.2 & +12.2 & +14.5 \\
$\mathbf{2}$ & -12.9 & -14.4 & -21.1 & -22.2 & -22.8 \\
$\mathbf{2} \mathbf{M e}$ & -12.1 & -8.7 & -16.3 & -17.2 & -18.0 \\
$\mathbf{2} \mathbf{M e}_{2}$ & +12.2 & +7.5 & +3.8 & +16.0 & +19.1 \\
\hline
\end{tabular}



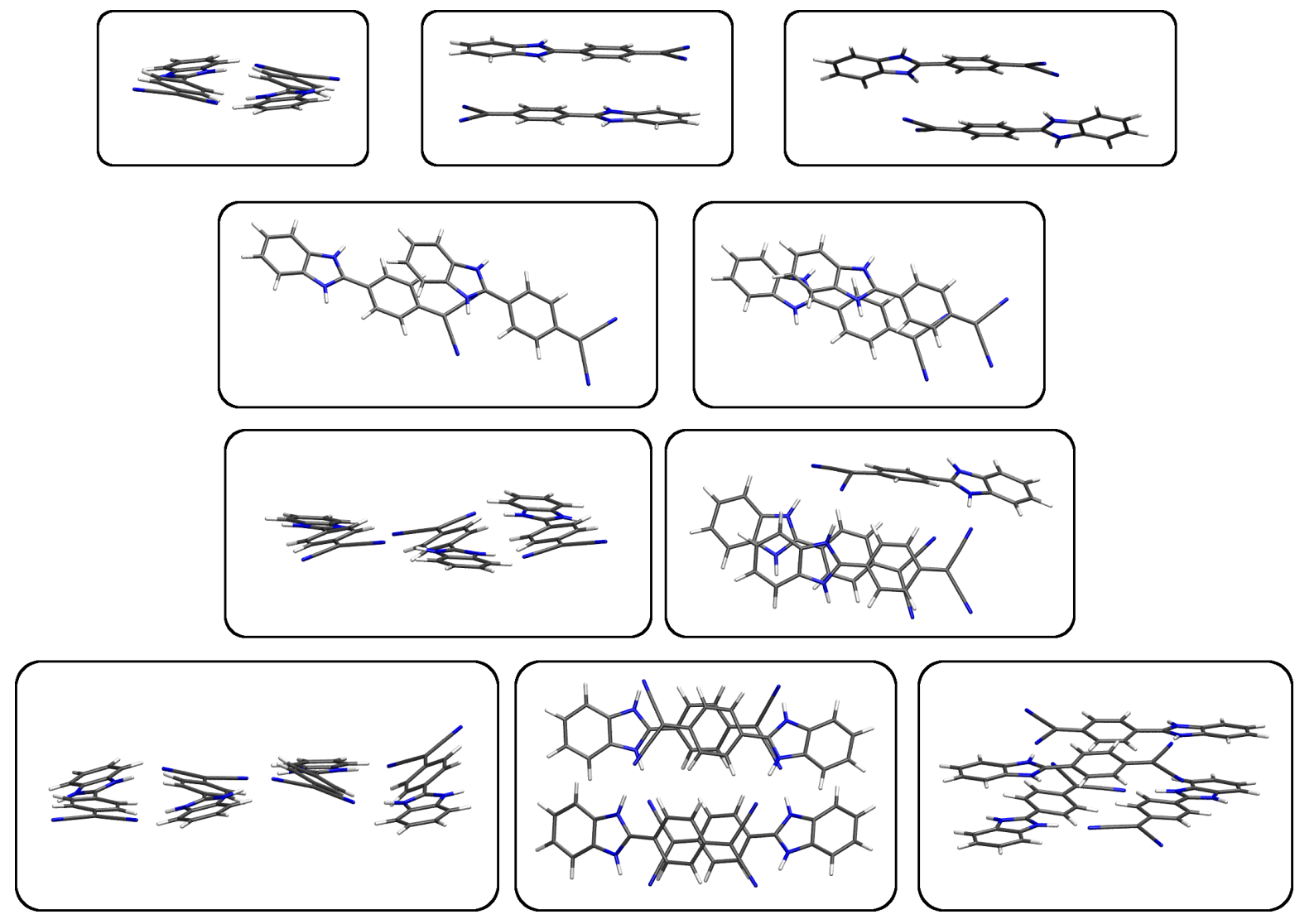

Figure S12: Conformational landscape of 2. Two top rows: dimers, middle: trimers, bottom: tetramers
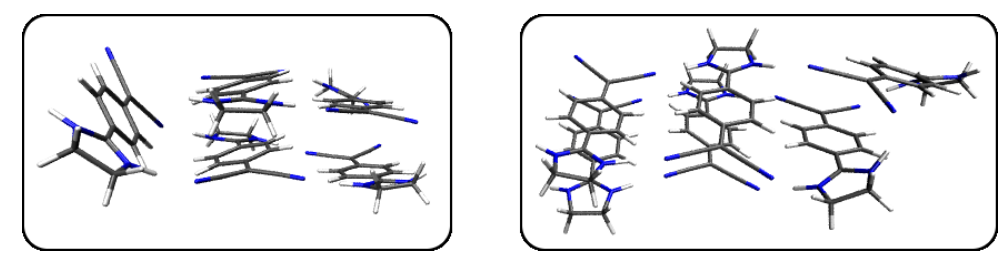

Figure S13: A pentamer (left) and a hexamer (right) of 1. 


\section{Excited state calculations}

Table S10: Comparison of experimental and calculated energetic shifts in $\mathrm{nm}$ relative to the computed monomer excitation wavelengths of compounds $1,1 \mathrm{Me}, 2$, and $2 \mathrm{Me}$ in the syn conformations computed at the SMD/BHLYP/def2-TZVP($\mathrm{f}) / \mathrm{MRCl}$ level. The experimental red-shifts and those obtained by the transient dimer species (see text) are given in $\mathrm{eV}$ as well for better comparability.

\begin{tabular}{ccccc}
\hline & $\mathbf{1}$ & $\mathbf{1 M e}$ & $\mathbf{2}$ & $\mathbf{2 M e}$ \\
\hline$\lambda_{\text {exc,mon }}$ (calc.) & 375 & 355 & 420 & 399 \\
$\lambda_{\text {exc,mon }}$ (exp.) & 355 & 344 & 392 & 366 \\
\hline $\mathrm{S}_{\mathrm{HT}}$ & +14 & +15 & +13 & +7 \\
$\mathrm{~S}_{\mathrm{ST}}$ & +17 & +31 & +17 & +28 \\
\hline exp. & +55 & +50 & +48 & +57 \\
exp. (eV) & -0.47 & -0.46 & -0.35 & -0.47 \\
transient & +41 & +34 & +37 & +47 \\
transient $(\mathrm{eV})$ & -0.33 & -0.31 & -0.24 & -0.33 \\
\hline
\end{tabular}

Table S11: Comparison of experimental and calculated values and energetic shifts in nm relative to the computed monomer excitation wavelengths of compounds $\mathbf{1}, \mathbf{1 M e}, \mathbf{2}$, and $\mathbf{2 M e}$ in all stable anti conformations computed at the SMD/ $\omega \mathrm{B} 97 \mathrm{X}$ D3/def2-TZVP level of TD-DFT. The experimental red-shifts and those obtained by the transient dimer species (see main text) are given in $\mathrm{eV}$ as well for better comparability. Note that there is a systematic overestimation of the excitation energies with respect to experiment and DFT/MRCI (cf. table 2 in the main text).

\begin{tabular}{ccccc}
\hline & $\mathbf{1}$ & $\mathbf{1 M e}$ & $\mathbf{2}$ & $\mathbf{2 M e}$ \\
\hline$\lambda_{\text {exc,mon }}$ (exp.) & 355 & 344 & 392 & 366 \\
$\lambda_{\text {exc,mon }}$ (calc.) & 327 & 314 & 352 & 334 \\
\hline $\mathrm{A}_{\mathrm{HB}}$ & -23 & -20 & -29 & -22 \\
$\mathrm{~A}_{\mathrm{ST}}$ & -15 & -8 & -7 & -6 \\
$\mathrm{~A}_{\mathrm{SD}}$ & -15 & -12 & -23 & -13 \\
\hline exp. & +55 & +50 & +48 & +57 \\
exp. (eV) & -0.47 & -0.46 & -0.35 & -0.47 \\
transient & +7 & +5 & +1 & +11 \\
transient $(\mathrm{eV})$ & -0.08 & -0.06 & -0.01 & -0.12 \\
\hline
\end{tabular}


Table S12: Comparison of experimental and calculated values and energetic shifts in nm relative to the computed monomer excitation wavelengths of compound 1 in all stable anti conformations computed at the M06-2X, ${ }^{[30]}$ B3LYP, ${ }^{[31]}$ CAMB3LYP, ${ }^{[32]} \omega \mathrm{B} 97 \mathrm{X}-\mathrm{D} 3, \omega \mathrm{B} 2 \mathrm{GP}-\mathrm{PLYP},{ }^{[33]}$ level of TD-DFT and $\mathrm{BHLYP} / \mathrm{MRCl}$, all in combination with the SMD solvent model and a def2-TZVP basis set.

\begin{tabular}{cccccccc}
\hline & M06-2X & B3LYP & CAM-B3LYP & $\omega$ B97X-D3 & $\omega$ B2GP-PLYP & BHLYP/MRCI & exp. \\
\hline$\lambda_{\text {exc,mon }}$ & 346 & 395 & 341 & 327 & 327 & 375 & 355 \\
\hline$A_{\mathrm{HB}}$ & -26 & $-*$ & -25 & -25 & -21 & -6 & \\
$\mathrm{~A}_{\mathrm{ST}}$ & -16 & $-*$ & -15 & -18 & -11 & +1 & +55 \\
$\mathrm{~A}_{\mathrm{SD}}$ & -7 & $-*$ & -8 & -15 & -13 & -1 & \\
metastable & +5 & +10 & +5 & +6 & +11 & +40 & \\
\hline
\end{tabular}

* The relevant transition did not show any oscillator strength or was not energetically located where expected.

Table S13: Detailed DFT/MRCI results for 1, 1Me, 2, and 2Me: Excitation wavelength is given in nm, transition dipole moments $M_{\text {trans }}$ in Debye, orbital contributions in \%. $f_{\text {osc }}$ is the oscillator strenght in length formalism. HOMO and LUMO are abbreviated as $\mathrm{H}$ and $\mathrm{L}$, respectively. The $S_{2}$ state is only analysed for the dimeric species. Oscillator strengths of zero are always due to the symmetry of the orbitals involved in the transition (see main text). Experimental values are given in the headings for comparison.

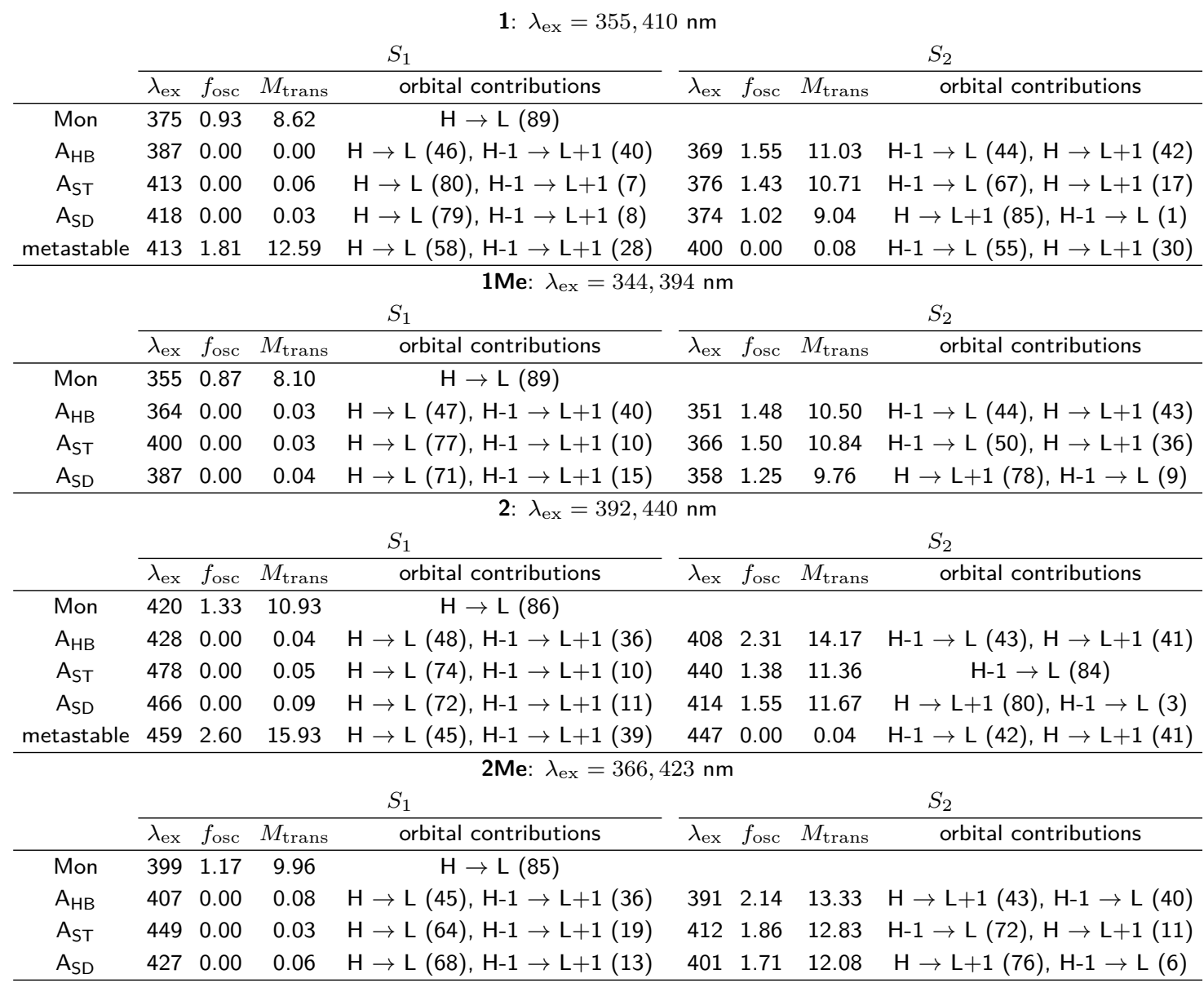


Table S14: Detailed TD- $\omega$ B97X-D3/def2-TZVP results for 1, 1Me, 2, and 2Me: Excitation wavelength is given in $\mathrm{nm}$, $f_{\text {osc }}$ is the oscillator strenght in length formalism. The $S_{2}$ state is only shown for the dimeric species. Oscillator strengths of zero are always due to the symmetry of the orbitals involved in the transition (see main text).

\begin{tabular}{|c|c|c|c|c|}
\hline \multicolumn{5}{|c|}{ 1: $\lambda_{\mathrm{ex}}=355,410 \mathrm{~nm}$} \\
\hline & $\overline{\lambda \lambda_{\mathrm{ex}}}$ & $f_{\text {osc }}$ & $\overline{\lambda_{\text {ex }}}$ & $f_{\text {osc }}$ \\
\hline Mon & 327 & 0.84 & & \\
\hline$A_{H B}$ & 321 & 0.00 & 304 & 1.45 \\
\hline$A_{S T}$ & 343 & 0.00 & 312 & 1.39 \\
\hline$A_{S D}$ & 349 & 0.00 & 312 & 1.00 \\
\hline metastable & 334 & 1.89 & 324 & 0.00 \\
\hline \multirow[t]{3}{*}{ 1Me: } & $\lambda_{\text {ex }}=$ & 344, & $94 \mathrm{~nm}$ & \\
\hline & & $s_{1}$ & $S$ & $\Phi_{2}$ \\
\hline & $\lambda_{\text {ex }}$ & $f_{\text {osc }}$ & $\lambda_{\mathrm{ex}}$ & $f_{\text {osc }}$ \\
\hline Mon & 314 & 0.78 & & \\
\hline$A_{H B}$ & 309 & 0.00 & 294 & 1.37 \\
\hline$A_{S T}$ & 334 & 0.00 & 306 & 1.34 \\
\hline$A_{S D}$ & 329 & 0.00 & 302 & 1.20 \\
\hline
\end{tabular}

2: $\lambda_{\mathrm{ex}}=392,440 \mathrm{~nm}$

\begin{tabular}{|c|c|c|c|c|}
\hline & \multicolumn{2}{|c|}{$S_{1}$} & \multicolumn{2}{|c|}{$S_{2}$} \\
\hline & $\overline{\lambda_{\mathrm{ex}}}$ & $f_{\mathrm{osc}}$ & $\lambda_{\mathrm{ex}}$ & $f_{\text {osc }}$ \\
\hline Mon & 352 & 1.24 & & \\
\hline$A_{H B}$ & 340 & 0.00 & 323 & 2.27 \\
\hline$A_{S T}$ & 379 & 0.00 & 345 & 1.54 \\
\hline$A_{S D}$ & 367 & 0.00 & 329 & 2.09 \\
\hline metastable & 353 & 2.81 & 343 & 0.00 \\
\hline
\end{tabular}

\begin{tabular}{|c|c|c|c|c|}
\hline & \multicolumn{2}{|c|}{$S_{1}$} & \multicolumn{2}{|c|}{$S_{2}$} \\
\hline & $\lambda_{\mathrm{ex}}$ & $f_{\mathrm{osc}}$ & $\lambda_{\mathrm{ex}}$ & $f_{\mathrm{osc}}$ \\
\hline Mon & 334 & 1.12 & & \\
\hline$A_{H B}$ & 327 & 0.00 & 312 & 2.12 \\
\hline$A_{S T}$ & 359 & 0.00 & 328 & 1.90 \\
\hline$A_{S D}$ & 344 & 0.00 & 321 & 1.88 \\
\hline
\end{tabular}




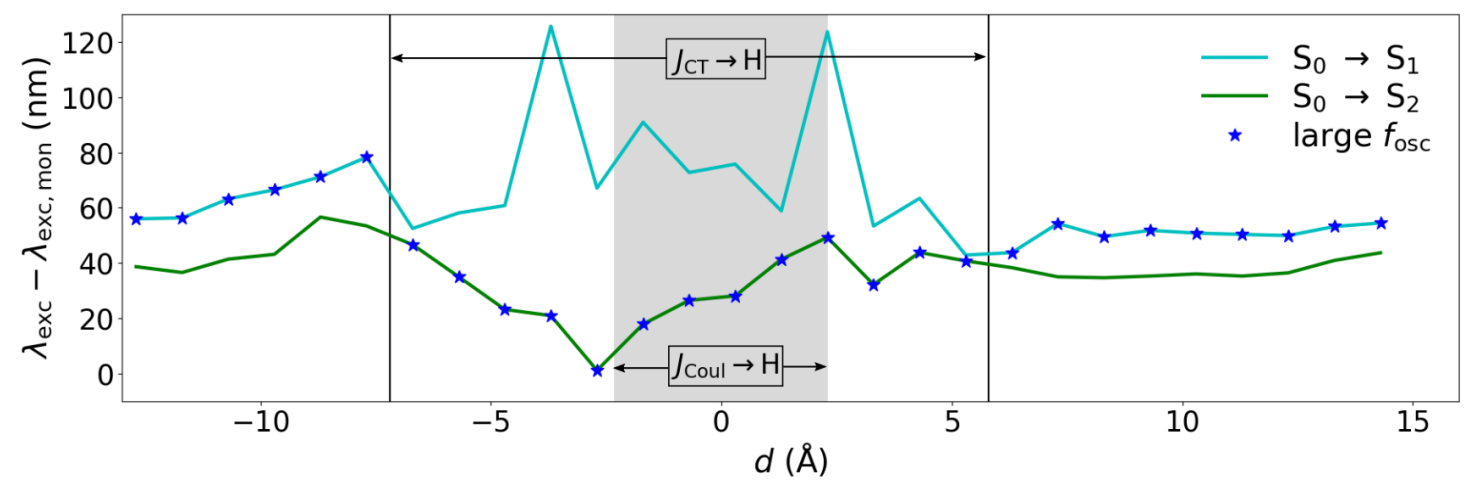

Figure S14: SMD/BHLYP/def2-SVP/MRCl excitation wavelength shift of the first two excited singlet states with respect to the computed monomer excitation wavelength $(420 \mathrm{~nm})$ of 2 . Darkblue Stars indicate the bright state. The grey shaded area and the two vertical lines encompass the $\mathrm{H}$-aggregate zones according to the definitions of $J_{\mathrm{Coul}}$ and $J_{\mathrm{CT}}$, respectively.

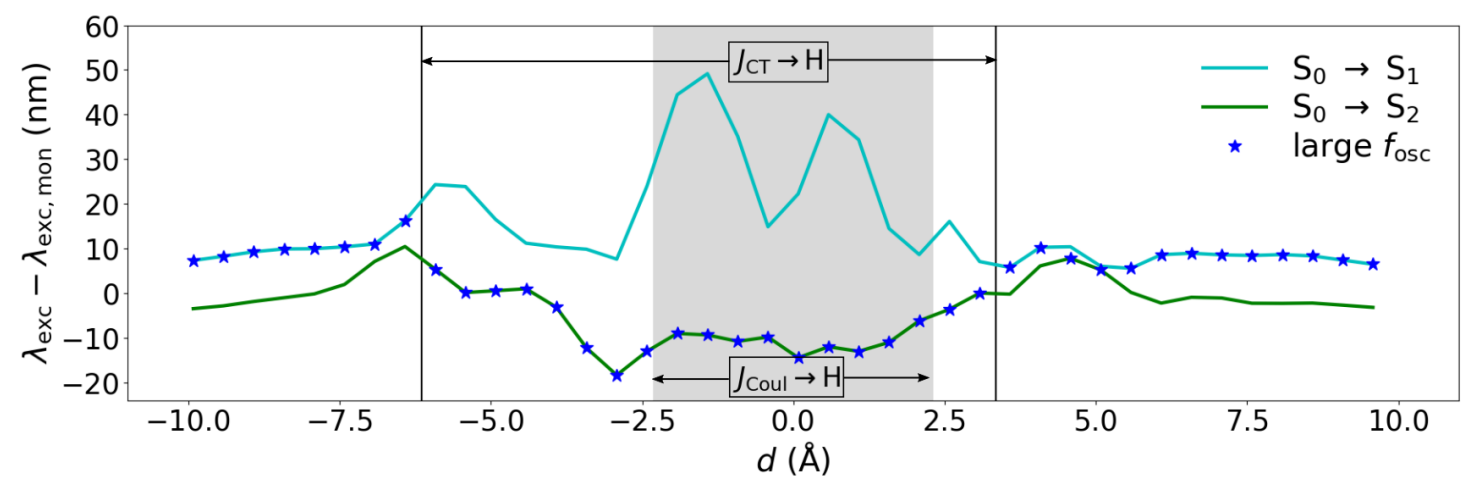

Figure S15: SMD/TD- $\omega$ B97X-D3/def2-TZVP excitation wavelength shift of the first two excited singlet states with respect to the computed monomer excitation wavelength $(327 \mathrm{~nm})$ of 1 . Darkblue Stars indicate the bright state. The grey shaded area and the two vertical lines encompass the $\mathrm{H}$-aggregate zones according to the definitions of $J_{\text {Coul }}$ and $J_{\mathrm{CT}}$, respectively.

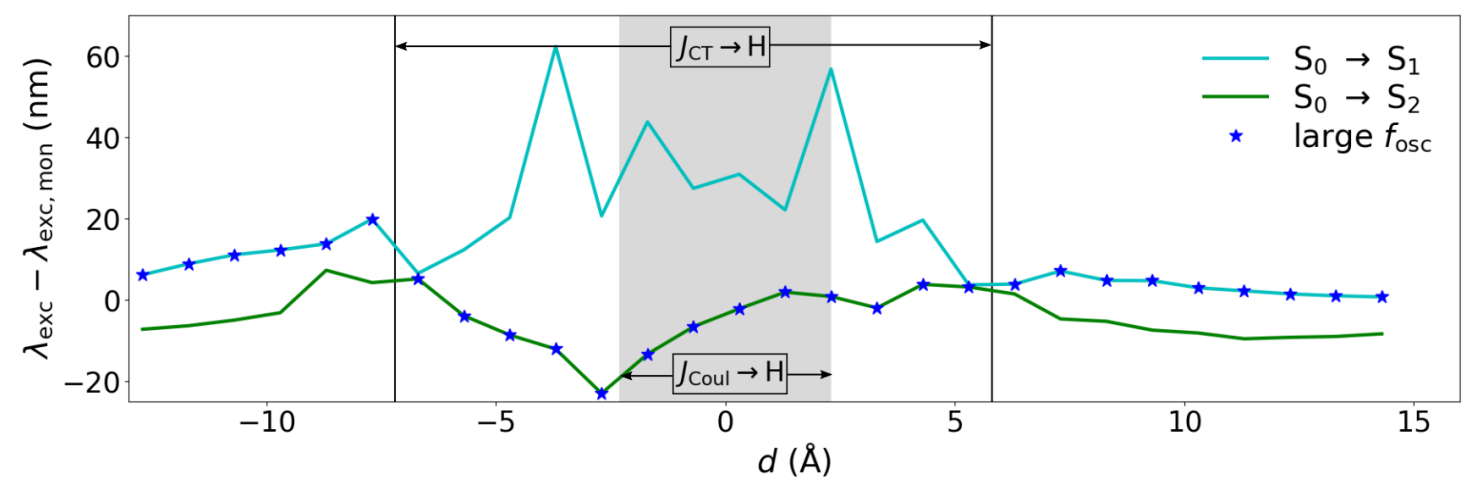

Figure S16: SMD/TD- $\omega$ B97X-D3/def2-TZVP excitation wavelength shift of the first two excited singlet states with respect to the computed monomer excitation wavelength $(352 \mathrm{~nm})$ of 2 . Darkblue Stars indicate the bright state. The grey shaded area and the two vertical lines encompass the $\mathrm{H}$-aggregate zones according to the definitions of $J_{\text {Coul }}$ and $J_{\mathrm{CT}}$, respectively. 
Table S15: Excitation wavelengths of the bright states and energetic shifts in $\mathrm{nm}$ relative to the computed monomer excitation wavelengths computed at the SMD/ $\omega$ B97X-D3/def2-TZVP level of the investigated trimers and tetramers of 1. Oscillator strengths are given in parentheses.

\begin{tabular}{ccccc} 
& $\mathrm{Q}_{\mathrm{A}}$ & $\mathrm{Q}_{\mathrm{S}}$ & $\mathrm{T}_{\mathrm{P}}$ & $\mathrm{T}_{\mathrm{S}}$ \\
\hline$\lambda_{\text {exc,mon }}$ & $308(0.49) / 296(1.64)$ & $302(2.16)$ & $318(0.27) / 297(1.76)$ & $326(0.27) / 300(1.31)$ \\
$\lambda_{\text {exc }}-\lambda_{\text {exc,mon }}$ & $-19 /-31$ & -25 & $-9 /-30$ & $-1 /-27$ \\
\hline
\end{tabular}




\section{AIMD simulations}

Ab-initio molecular dynamics simulations were conducted using the GFN2-xTB ${ }^{[3]}$ code to assess the possibility of encountering metastable dimers of $\mathbf{1}-\mathrm{A}_{\mathrm{ST}}$. No explicit solvent molecules were used. Instead, the GBSA solvent model as implemented in the program was used for acetonitrile. The run lasted 75 ps before the dimer dissociated due to the energy being drained into rotational motion. This effect is an artifact of the algorithm and is known as "flying ice cube". ${ }^{[34]}$ Nevertheless, conformational changes seemed sufficiently fast to warrant a conclusive analysis of the simulation. More accurate simulations employing more sophisticated methods and large explicit solvent cavities could not be achieved for useful time scales.

A time step of $0.5 \mathrm{fs}$ in combination with the Berendsen thermostat ${ }^{[35]}$ set to $293 \mathrm{~K}$ was used. Structures were written out every 10 steps, or $5 \mathrm{fs}$. The obtained trajectory was aligned by a translational and rotational fit with the positions of one mononmer in the starting frame as reference. Subsequently, the root-mean-square deviation (RMSD) of atomic positions throughout the simulation was calculated with the same reference. Density-based density-peaks clustering was used to cluster the RMSD time-series where as a result 4 clusters were selected (density-cutoff $\rho=100$, distance-cutoff $\delta=0.02$, Figure S17). ${ }^{[36]}$

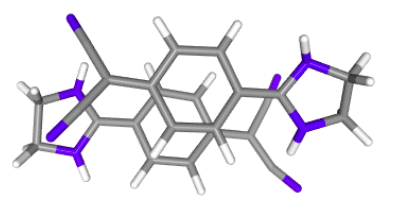

1: $22.7 \%$

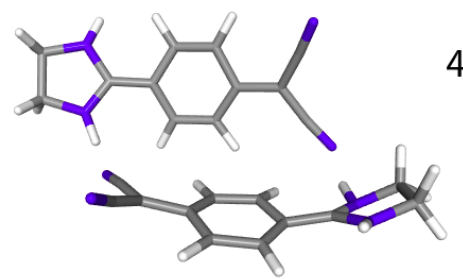

3: $7.6 \%$

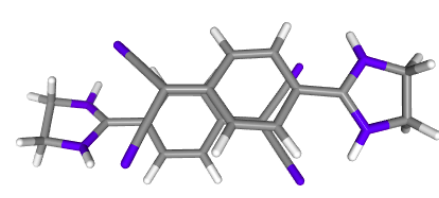

2: $30.4 \%$

4: $36.4 \%$
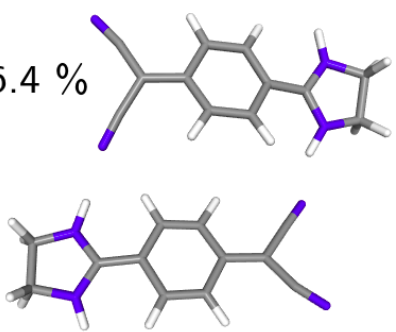

Figure S17: Representative snapshots for identified dimer orientations extracted by density-peaks clustering. A label indicates the relative population among all identified dimer states.

Among the identified dimers are stacked anti-parallel structures resembling 1-A of shifting along longitudinal displacement coordinate $d$ (clusters 1 and 2) besides flat hydrogen-bonded dimers comparable to $1-\mathrm{A}_{\mathrm{HB}}$ (clusters 3 and 4 ). The stacked dimers show projected COM distances as illustrated in Figure S18. About $20 \%$ of the structures show a distance below $-3 \AA$ resembling a metastable dimer.

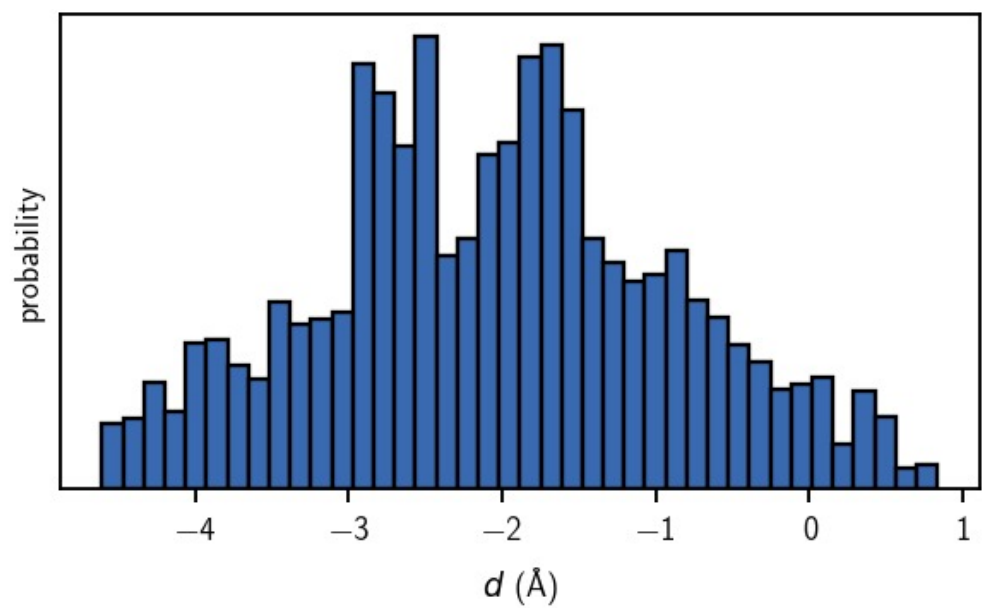

Figure S18: Histogram of the COM distance between the two monomers considering only stacked dimers. 


\section{Coordinates of molecular structures of all dimers}

All SCF energies are given in Hartree at the $\omega$ B97X-D3/def2-QZVP level of DFT. All structures represent minima on their respective potential energy surface.

\section{1-A}

Energy $=-1361.609308247$

N $-0.44197746 .2691284-1.0838224$

C $-0.33922795 .1836179-0.6875822$

C $-0.20224213 .8743497-0.2089482$

C - -1.36291163 .22171700 .2037037$

N -2.3162466 2.65417970 .5457166

C $1.07109993 .2079446-0.1829668$

C $2.23336903 .8242835-0.6857251$

C $3.44612973 .1752048-0.6800136$

C $3.56509841 .8754402-0.1750025$

C 2.41979211 .25848030 .3402284

C 1.20753031 .90732260 .3408284

H 0.35018671 .40110200 .7664876

H 2.47523310 .26733040 .7712552

C $4.83658261 .1871852-0.1904647$

N $6.00941711 .7904014-0.3025170$

C $7.10877880 .8452254-0.1537600$

C $6.3828057-0.5043747-0.2574091$

N $4.9855800-0.1183644-0.1053420$

H $4.2257986-0.7917182-0.2276542$

H $4.30201503 .6844810-1.1050643$

H $2.18161614 .8225066-1.1010479$

N $1.0239380-5.74307001 .2159484$

C $0.9211788-4.65806880 .8183254$

C $0.7841821-3.34933850 .3382256$

C $1.9450111-2.6969864-0.0745291$

N $2.8984864-2.1298008-0.4167138$

C $-0.4892269-2.68311630 .3114184$

C $-0.6255849-1.3825750-0.2126066$

C $-1.8378264-0.7337367-0.2122332$

C $-2.9832388-1.35065190 .3028424$

C $-2.8644554-2.65053860 .8076363$

C - $1.6516865-3.29959990 .8135926$

H -1.6001281 -4.2980652 1.2283582

H -3.7205511 -3.1598648 1.2321986

C $-4.2546241-0.66226570 .3184991$

N -5.4274758 -1.26544660 .4308546$

C $-6.5267800-0.32031760 .2811298$

C -5.8008704 1.02930610 .3846917

N -4.4036201 0.64327770 .2329361

H -3.6438327 1.31659560 .3554097

H - $1.89313290 .2573936-0.6433261$

H $0.2318030-0.8764527-0.6382795$

H -5.5502756 - 2.25208910 .2701673

H $6.13230122 .7770513-0.1420130$

H $6.5341690-0.9777620-1.2281828$

H $6.6845083-1.20403990 .5189095$

H $7.85459940 .9829399-0.9331865$

H 7.58918780 .98080290 .8157233

H -7.2730197 -0.45769421 .0601929$ 
H -7.0065557 -0.4561435 -0.6886079

H -5.9523614 1.50289211 .3553690

H -6.1024090 $1.7289488-0.3917284$

\section{1-A $\mathbf{A}_{\mathrm{ST}}$}

Energy $=-1361.606643984$

N -4.4208466 3.27373984 .4908444

C -4.3919811 2.1339412 4.7093142

C - 4.35440760 .75769274 .9618547

C -5.5224841 0.17524175 .4673716

N $-6.4910362-0.31344165 .8806521$

C -3.1696037 -0.0150459 4.7327432

C -1.98952740 .57684814 .2405899$

C $-0.8499230-0.16300624 .0404429$

C $-0.8171121-1.53555884 .3142615$

C $-1.9913818-2.13440944 .7863165$

C -3.1335276 -1.3998598 4.9909010

H -4.0177589 -1.9060308 5.3563833

H -1.9668407 1.63552864 .0166552

H 0.02504260 .35473263 .6689180

H -2.0331741 -3.1955294 4.9960114

C $0.3925578-2.30202064 .1382841$

N $1.5248748-1.83168473 .6486372$

H $1.6635944-0.88151653 .3517598$

C $2.6072076-2.80179333 .7160182$

H $3.0592189-2.94505602 .7370301$

H $3.3794272-2.45964594 .4048338$

C $1.8864036-4.06213484 .2269816$

H $2.3255444-4.44446215 .1467634$

H $1.8737967-4.86593023 .4923991$

N $0.5393705-3.57048394 .4726157$

H -0.1749171 -4.1313347 4.9033294

N $0.8422862-6.38407481 .2302190$

C $0.8126150-5.24367451 .0150960$

C $0.7739573-3.86677690 .7663248$

C $1.9421054-3.28173370 .2639769$

N $2.9107295-2.7909258-0.1465860$

C - $0.4118061-3.09586410 .9964405$

C - $1.5905290-3.68943011 .4899032$

C - $2.7309862-2.95119951 .6912122$

C - $2.7662134-1.57877911 .4170838$

C $-1.5932903-0.97830750 .9436235$

C - $0.4502538-1.71115180 .7380867$

H $0.4325337-1.20384120 .3707051$

H -1.6112276 -4.7479935 1.7146099

H -3.6044944 -3.4698967 2.0648636

H -1.5534778 0.08257600 .7324471

C -3.9768664 -0.8139897 1.5937614

N -4.1229000 0.45656811 .2672590

H -3.4066658 1.02074570 .8443149

C -5.4727636 0.94451601 .5043577

H -5.4667190 1.75114692 .2357721

H -5.9084730 1.32176710 .5807278

C -6.1921440 -0.31627832 .0166914$

H -6.6384709 -0.1745823 2.9986374 
H -6.9688281 -0.65591471 .3317660$

N -5.1108226 -1.28798912.0760201

H -5.2506865 -2.2401553 2.3658934

\section{1-A}

Energy $=-1361.606006042$

N -4.6102486 3.25171354.2882318

C -4.50093452 .13984344 .6115369$

C - 4.40710740 .79936134 .9876119

C -5.5918111 0.20987965 .4469956

N -6.5755804 -0.2734646 5.8281064

C -3.2093749 0.03651224 .7969301

C - 2.02889320 .63066924 .3086800

C $-0.8906608-0.10902774 .1009492$

C $-0.8709880-1.48391174 .3642952$

C $-2.0336893-2.08298444 .8632010$

C -3.1678754 -1.3417637 5.0849373

H -4.0477457 -1.8393050 5.4717403

H -2.0155745 1.68570624 .0671576

H -0.0205926 0.38440963 .6865317

H -2.0498582 -3.1393312 5.0996254

C $0.2972407-2.27335694 .0760730$

N $1.5293095-1.80298073 .9977242$

H $1.7922305-0.90290694 .3657892$

C $2.4992726-2.87327443 .8069629$

H $3.2151666-2.62409193 .0272411$

H $3.0431355-3.05364574 .7348929$

C $1.5944090-4.05450463 .4301031$

H $1.8639400-4.97181333 .9480847$

H $1.6000610-4.24805352 .3563915$

N $0.2800606-3.57749363 .8444596$

H -0.5674098 -4.0478203 3.5506755

N -2.2703862 -4.2003750 2.0760284

C - $2.3824016-3.08855101 .7534613$

C -2.4793600 -1.7481895 1.3778734

C - $1.2961616-1.15557030 .9184420$

N -0.3140937 -0.66902390 .5371827$

C -3.6785488 -0.98790311 .5692510$

C - $4.8571468-1.58396082 .0598343$

C -5.9961376 -0.8460909 2.2698439

C -6.0187793 0.52869442 .0060488

C -4.85839121 .12930971 .5035823$

C -3.7233904 0.38999731 .2798499

H -2.84545170 .88883840 .8903620$

H -4.8680586 -2.6388468 2.3021292

H -6.8642652 -1.3408671 2.6867078

H -4.8444905 2.1854961 1.2662631

C -7.1864064 1.31696602 .2996496

N -7.1691679 2.6216930 2.5287342

H -6.3203853 3.09328982 .8163744

C -8.4809690 3.09793422 .9520650

H -8.4784045 3.29474174 .0251242

H -8.7559882 4.01316332 .4332758

C -9.3871455 1.91422482 .5860547

H -10.0947305 1.66486173 .3732906 
H -9.9407473 2.09188261 .6634012 N -8.4172555 0.84539732 .3874640

H -8.6820831 -0.0560524 2.0241705

\section{$1-\mathrm{S}_{\mathrm{HT}}$}

Energy $=-1361.595580613$

N 1.83437594 .55634800 .2042101

C 1.78787963 .79639281 .0800732

C 1.72301202 .87716182 .1348707

C 2.88838882 .69525112 .8902855

N 3.84995712 .53926873 .5210697

C 0.52028492 .15719372 .4284594

C -0.6517994 2.3382228 1.6641990

C - 1.80540961 .64940411 .9497193

C - 1.85702230 .73456993 .0096489

C -0.69808770 .54418863 .7735945$

C 0.45557271 .23551923 .4947670

H 1.32470091 .06559154 .1171200

H -0.6947648 -0.13540664 .6166289$

C -3.0672822 0.01048443 .3060796

N -4.2662579 0.32294022 .8438336

C -5.3025706 -0.51790863 .4296674$

C -4.4759920 -1.63511134.0805367

N -3.1368984 -1.05996434.0777101

H -2.3276480 -1.5968289 4.3444144

H -2.6683122 1.81429911 .3166637

H -0.65296293 .02752280 .8296549$

N -7.2485709-2.4481058 5.9053096

C -8.1497684 -2.2354677 5.2050587

C $-9.2448340-1.98784844 .3682853$

C -9.0428485 -1.0928704 3.3102125

N -8.8762169 -0.35288222 .4316691$

C $-10.5101004-2.62388454 .5830959$

C -11.6115291 -2.3764110 3.7370437

C -12.8250722 -2.9849796 3.9465087

C -13.0100096 -3.8809192 5.0076751

C - $11.9221450-4.13691585 .8525469$

C - $10.7090354-3.52532445 .6498667$

H -9.8981786 -3.7436594 6.3328312

H -12.0223813 -4.8045120 6.6991627

C -14.2826541 -4.5219140 5.2236115

N -14.4735684 -5.5810470 5.9914900

C - $15.8429770-6.07122675 .8973418$

C $-16.5505139-4.90288845 .1978823$

N -15.4245988 -4.1343096 4.6821815

H -15.5498466 -3.2286746 4.2596311

H -13.6293795 -2.7722950 3.2533573

H -11.5091281 -1.6991972 2.8988840

H -15.8717629 -6.9847390 5.3024522

H -16.2533993 -6.2831917 6.8816522

H -17.2056764 -5.2285312 4.3935317

H -17.1283982 -4.2953177 5.8951081

H -13.7202266 -6.1706438 6.3066559

H -5.9858292 -0.88533822 .6678918$

H -5.8736753 0.05105764 .1645024 
H -4.4889001 -2.5532495 3.4921772

H -4.8095925 -1.8621585 5.0894989

H -4.4779867 1.21977862 .4374639

\section{$1-\mathrm{S}_{\mathrm{ST}}$}

Energy $=-1361.600664080$

N $4.08761233 .6049562-2.5602314$

C $3.92513433 .0445597-1.5571816$

C $3.72142882 .3871760-0.3380758$

C 4.86608901 .97170010 .3531373

N 5.81207231 .63404210 .9341239

C 2.41073552 .08517260 .1388832

C $1.25863932 .4475678-0.5895103$

C $0.00186832 .1260426-0.1433282$

C - 0.18585361 .43470961 .0606031

C 0.95535951 .08554311 .8005438

C 2.21214901 .40374501 .3594156

H 3.06443291 .10533841 .9556606

H 0.86833200 .56477062 .7457200

C - 1.49778721 .06859581 .5094831

N -2.6378368 1.46457740 .9500539

C -3.7855272 1.07906711 .7619423

C -3.1779535 0.02866132 .6986951

N -1.7541691 0.28256352 .5415067

H -1.0543836 -0.2660683 3.0123158

H -0.8414063 2.3990732 -0.7653465

H $1.35768452 .9657654-1.5344451$

N $4.2138860-2.04798651 .4834133$

C $3.6753374-1.67098410 .5273092$

C $3.0126847-1.2262506-0.6234436$

C $3.8079184-0.7116409-1.6565544$

N $4.4620870-0.3095086-2.5257866$

C $1.5913733-1.2766628-0.7282432$

C $0.9172113-0.7464627-1.8492875$

C $-0.4501010-0.7706426-1.9378373$

C $-1.2324176-1.3403278-0.9222613$

C - $0.5720098-1.89978640 .1817848$

C $0.7949658-1.86150370 .2818520$

H $1.2640477-2.28594031 .1599716$

H -1.1302951 -2.3528653 0.9918843

C - $2.6656666-1.3361428-1.0032424$

$\mathrm{N}-3.4739507-2.0428976-0.2200888$

C $-4.8594210-1.9453979-0.6664180$

C $-4.8049207-0.7409889-1.6140569$

N -3.3749564 -0.6173789-1.8555258

H -2.9879663 $0.1314527-2.4057911$

H -0.9107621 -0.3496009-2.8229077

H $1.4828828-0.2912507-2.6515227$

H -3.1501949-2.8547627 0.2811102

H -5.1511015 -2.8596394-1.1843286

H -5.5347526 -1.7922146 0.1720633

H -5.3485580 -0.9092197-2.5405526

H -5.1886908 $0.1701201-1.1518124$

H -3.4174595 -0.9896912 2.3896001

H -3.4889620 0.15779913 .7325626 
H -4.5907228 0.67948911 .1492399

H -4.1683087 1.94214122 .3079047

H -2.6815061 2.26700030 .3432810

\section{Me-A $_{\mathrm{HB}}$}

Energy $=-1440.049649916$

$\mathrm{N}-0.53603406 .0251403-1.2883374$

C - $0.39221434 .9846046-0.7949718$

C - $0.20434673 .7307754-0.2006718$

C - 1.32365593 .12070720 .3614771

N -2.2470400 2.59554260 .8313914

C $1.08265133 .0845942-0.1914399$

C $2.19839063 .6673510-0.8201819$

C $3.42968063 .0509858-0.8107411$

C $3.60917191 .8176037-0.1770068$

C 2.50483371 .22187680 .4405803

C 1.27571021 .84170260 .4405767

H 0.45043071 .35456590 .9444636

H 2.61041480 .27269910 .9497486

C $4.88911071 .1306318-0.1970695$

N $6.07548081 .7001990-0.0745577$

C $7.14051900 .7161560-0.2567774$

C $6.3787056-0.6161044-0.2757349$

N $4.9954928-0.1729581-0.3467231$

H $4.2106777-0.8011879-0.5339500$

H $4.24807403 .5260573-1.3357796$

H $2.09853684 .6149050-1.3339459$

N $1.1363206-5.47782941 .4310394$

C $0.9861749-4.44347050 .9267157$

C $0.7910510-3.19703000 .3192663$

C $1.9051440-2.5911707-0.2578348$

N $2.8242789-2.0696811-0.7401109$

C $-0.4973546-2.55377720 .3118929$

C $-0.6976635-1.3184240-0.3325456$

C - $1.9281387-0.7015312-0.3311636$

C - $3.0270104-1.29285370 .3002840$

C $-2.8402099-2.51846270 .9469543$

C $-1.6073856-3.13180070 .9550299$

H - $1.5017087-4.07312521 .4789593$

H -3.6537582 -2.9892921 1.4831155

C $-4.3085148-0.60894550 .3201870$

N -5.4943291 -1.18266630 .2122294$

C $-6.5604160-0.19886180 .3896560$

C -5.8017638 1.13525700 .3843303

N -4.4171769 0.69620470 .4541618

H -3.6324985 1.32857740 .6278182

H - $2.03928570 .2417264-0.8501066$

H $0.1231183-0.8350778-0.8473912$

C - $5.8019307-2.5579064-0.0954263$

C 6.38412553 .07067140 .2527025

H $6.6323796-1.2263591-1.1397229$

H $6.5472973-1.20652150 .6254844$

H $7.67463780 .9111681-1.1882172$

H 7.85176830 .78025420 .5654085

H -7.0864565 -0.3824829 1.3279986 
H -7.2781557 -0.2757651 -0.4257472

H -6.05225051 .75791921 .2403521$

H -5.9765574 $1.7114969-0.5248430$

H -6.6326621 -2.5820924 -0.7987592

H -6.0896631 -3.1129628 0.7979165

H -4.9509648 -3.0465383-0.5613733

H 5.53108783 .55542650 .7189287

H $6.67927493 .6363131-0.6315225$

H 7.21006963 .08395130 .9619571

\section{$1 \mathrm{Me}-\mathrm{A}_{\mathrm{ST}}$}

Energy $=-1440.044051886$

N -6.9659971 4.93887296.3981302

C -6.9993568 3.78963926 .2375239

C -7.0362156 2.40541706 .0330796

C -8.2872602 1.78600686 .1179641

N -9.3221480 1.26508666 .1998505

C -5.8408989 1.64798985 .7922268

C -4.56459442 .23456025 .8996775$

C -3.4219668 1.49920255 .6961023

C -3.4837967 0.13984615 .3626370

C $-4.7481445-0.44375145 .2221047$

C -5.8920932 0.28616965 .4405908

H -6.8489918 -0.20522345 .3198795$

H -4.4695010 3.27837936 .1703767

H -2.4662646 1.99075935 .8295724

H -4.8534346 -1.4693655 4.8981361

C - $2.2598223-0.59189625 .1221470$

N -1.1596604 -0.0150390 4.6660100

H -1.0986431 0.95595104 .4120582

C - $0.0239432-0.92130154 .6792049$

C $-0.7274439-2.26864134 .8377783$

N -2.0499137 -1.8819891 5.3285905

C -2.9261863 -2.8560570 5.9322978

N -2.4441533 -3.8472344 1.1370501

C -2.4058046 -2.6973171 1.2916107

C -2.3628160 -1.3122234 1.4889459

C - $1.1091876-0.69872021 .3983604$

N -0.0719498 -0.18340281 .3111044$

C -3.5547566 -0.54886731 .7277097$

C - $4.8335750-1.13058991 .6232276$

C -5.9729652 -0.38980621 .8253233$

C -5.9050715 0.97027582 .1543454

C -4.6382433 1.54934412 .2917124

C -3.4975455 0.81407422 .0743705

H -2.5384600 1.30181012 .1923365

H -4.9334403 -2.1748380 1.3558229

H $-6.9308851-0.87768061 .6942954$

H -4.5286375 2.57564862 .6121555

C -7.1255357 1.70812872 .3933933

N -7.3296775 2.99828342 .1821665

C -6.4510534 3.96473071 .5698894

C -8.6495538 3.39337912 .6730254

C -9.35903542.0500182 2.8390601

N -8.2277778 1.13815132 .8530536 
H -8.2923254 0.16900223 .1130299

H -5.8893220 4.5306795 2.3142498

H -7.0542934 4.6628310 0.9931233

H -5.7576755 3.47900640 .8890080

H -2.3213617 -3.5557583 6.5054591

H -3.4843306 -3.4190482 5.1829525

H -3.6230076 -2.3778599 6.6150370

H $-0.2325647-2.91821805 .5568261$

H - $0.8255234-2.80886763 .8926485$

H $0.6328475-0.69601985 .5214883$

H $0.5445938-0.84652543 .7570106$

H -9.1423255 4.04164401 .9512404

H -8.5476545 3.93824333 .6150328

H -10.01904141.82402331.9994885

H -9.9256134 1.98186773 .7628970

\section{Me-A}

Energy $=-1440.047042174$

N -4.7066699 2.86976475.5322972

C - 4.68344731 .72597545 .3365553

C - 4.65885520 .34611705 .0992188

C $-5.9026025-0.27749235 .0212563$

N -6.9569229 -0.76534284 .9521067$

C - $3.4308561-0.35498994 .8539074$

C - 2.19167090 .31079724 .8950705

C - $1.0149014-0.35349384 .6445143$

C - $1.0098859-1.72421694 .3644943$

C $-2.2359019-2.39793214 .3220640$

C - $3.4143022-1.73082784 .5586385$

H -4.3446956 -2.2797691 4.4898311

H -2.1536994 1.36927485 .1183371

H -0.0840210 0.1975520 4.6900198

H -2.2793854 -3.4448899 4.0524012

C $0.2347891-2.38566174 .0388839$

N $1.2071621-1.78067493 .3736101$

H $1.0313958-0.94231612 .8295740$

C $2.2887859-2.69874613 .0499776$

C $1.9024651-3.94803933 .8522559$

N $0.5644132-3.62703514 .3448457$

C - $0.0919021-4.51345375 .2770169$

N -2.1693063 -3.3281015 0.7876077

C $-2.1873122-2.18445020 .9846231$

C $-2.2064796-0.80473501 .2230903$

C - $0.9608612-0.18508181 .3017727$

N 0.09429760 .30078041 .3716581

C - $3.4318680-0.09929481 .4688293$

C $-4.6734270-0.76065511 .4286032$

C - $5.8475423-0.09221611 .6806543$

C -5.8472543 1.27834171 .9613664

C - 4.61889041 .94787022 .0020788

C -3.4432209 1.27667281 .7638500

H -2.5108243 1.82232511 .8314357

H -4.7153857 -1.8189736 1.2052958

H -6.7804239 -0.6399379 1.6360389

H - 4.57142422 .99461352 .2718966 
C -7.0886764 1.94348792 .2915391

N -7.4155822 3.18627061 .9886824

C -6.7606409 4.07116681 .0540652

C -8.7522077 3.50925332 .4840159

C - 9.13732732 .26193353 .2898126

N -8.0604345 1.34063482 .9596688

H -7.8858509 0.49961023 .4996327

H -6.2543476 4.8852986 1.5717272

H -7.5094958 4.49788240 .3878740

H -6.0392675 3.52863170 .4501502

H $0.6558801-4.94079675 .9439794$

H -0.5968830 -5.3271961 4.7574404

H -0.8146719 -3.9720372 5.8803054

H $2.5667057-4.11776294 .7012613$

H $1.8840099-4.85372203 .2472583$

H $3.2537424-2.29247513 .3460390$

H $2.3107145-2.88968301 .9770580$

H -9.4183093 3.67739491 .6361222

H -8.7318346 4.41624323.0869300

H -10.1054316 1.85844773 .0003560

H -9.1515392 2.4539100 4.3627436

\section{$1 \mathrm{Me}-\mathrm{S}_{\mathrm{HT}}$}

Energy $=-1440.036021237$

N $2.26066582 .3948539-1.2190872$

C $2.06800191 .8790164-0.1970126$

C 1.82317141 .25503061 .0315823

C 2.91855681 .07966571 .8849387

N 3.82112240 .93058202 .5998402

C 0.50759690 .81147351 .3982729

C - 0.59432060 .98846230 .5378705

C - 1.85611410 .56798210 .8906177

C - $2.0834961-0.06295762 .1184409$

C - $0.9954589-0.25887802 .9769202$

C 0.26301790 .17595132 .6322497

H 1.07385970 .02156583 .3324924

H -1.1375623 -0.73316303 .9402258$

C -3.3891559-0.57218592.4861060

N -4.5517492 -0.0003269 2.2411014

C -5.6517883 -0.80854502 .7655237$

C -4.9473271 -2.0686104 3.2860391

N -3.5446354 -1.7123250 3.1376956

H -2.8068962 -2.39475813.2060226

H -2.6628604 0.70157470 .1815444

H -0.4572417 $1.4579424-0.4278353$

N -7.5937744 -2.2627132 5.4673598

C -8.4933970 -2.2940004 4.7334260

C $-9.5800786-2.32805783 .8527626$

C -9.4148090 -1.6723311 2.6273259

N -9.2737288 -1.1307994 1.6098119

C - $10.8049390-2.99554684 .1944304$

C -11.9136804 -2.9888939 3.3246654

C -13.0916866 -3.6152210 3.6610360

C - $13.2175191-4.30462774 .8723428$

C $-12.1232264-4.32375185 .7438800$ 
C -10.9516209 -3.6800827 5.4173664

H -10.1343616 -3.7029742 6.1270770

H -12.1937959-4.8140797 6.7063096

C -14.4817729 -4.91878025 .2270189$

N -14.6424840 -6.0641500 5.8587997

C -16.0623617 -6.3656593 6.0373405

C - $16.7570008-5.09613315 .5288346$

$\mathrm{N}-15.6474155-4.36331384 .9362842$

H -15.7242499 -3.3908850 4.6838878

H -13.9160608 -3.58887222 .9590431$

H -11.8511877 -2.4804552 2.3708343

H -16.3177719 -7.2453727 5.4444109

H -16.2820762 -6.5806671 7.0820381

H $-17.5300145-5.30566714 .7927680$

H $-17.1974278-4.51544256 .3389056$

H -6.3803320 -1.0184196 1.9828876

H -6.1538236 -0.25692783 .5619794$

H -5.1740502 -2.9473382 2.6830626

H -5.1941891 -2.2843359 4.3229843

C -13.6518331 -7.0845097 6.1127786

H -12.7412060 -6.8871300 5.5547627

H -14.0474672 -8.0472364 5.7912672

H -13.4159904 -7.1444004 7.1745291

C -4.8011336 1.34914831 .7910718

H -3.8935210 1.94384641 .8323180

H -5.5394560 1.80925982 .4469334

H -5.1882325 1.35677080 .7726772

\section{$1 \mathrm{Me}-\mathrm{S}_{\mathrm{ST}}$}

Energy $=-1440.039500568$

N 4.6568379 $3.1393828-2.2507509$

C $4.37475612 .7589940-1.1913031$

C 4.03178682 .32629200 .0957051

C 5.07775042 .20131811 .0173461

N 5.94512082 .10651741 .7830450

C 2.67642422 .04700010 .4588600

C $1.63518072 .0941106-0.4894624$

C $0.33770281 .8188396-0.1397375$

C - 0.00325411 .47601351 .1765835

C 1.02114021 .45050272 .1330256

C 2.32089801 .72493581 .7841744

H 3.07967951 .70087512 .5553121

H 0.80366211 .25428773 .1739291

C - 1.37505251 .16948951 .4944342

N -2.3973160 1.68261660 .8081831

C -3.6717405 1.36190701 .4325303

C -3.2698346 0.28082812 .4384290

N -1.8109424 0.35765872 .4405287

C - $1.0549283-0.55933253 .2618602$

H -0.4158152 $1.8286762-0.9165565$

H $1.85778012 .3192319-1.5244990$

N $4.2304808-1.46587241 .1354083$

C $3.6313433-1.27785970 .1598139$

C $2.8999620-1.0649023-1.0151641$

C $3.6148888-0.6407012-2.1419604$ 
N $4.1979417-0.3099590-3.0891236$ C $1.4807607-1.2161151-1.0484950$ C $0.7299474-0.9005232-2.2011391$ C $-0.6409505-0.9813621-2.2117658$ C $-1.3462691-1.4107919-1.0785956$ C - $0.6050180-1.79600100 .0474529$ C $0.7629224-1.69058950 .0695115$ H $1.2935692-1.96932830 .9709607$ H -1.1098114 -2.1655732 0.9316308 C $-2.7860782-1.5073872-1.0516113$ N -3.4266355 -2.4293260 -0.3443223 C $-4.8694684-2.3549472-0.5190161$ C $-5.0189406-1.1608631-1.4723588$ N -3.6413633 - $0.7135502-1.6705909$ C -3.3769923 $0.5243061-2.3640075$ H -1.1631314 -0.7380609-3.1275735 H $1.2347072-0.5691841-3.0994814$ H -2.9703170 -3.2638007-0.0128773 H -5.2468379 -3.2785506 -0.9532474 H -5.3694110 -2.1958165 0.4354635 H -5.4693508 -1.4331564-2.4270318 H -5.6094817 -0.3525210 -1.0400977 H -3.5753634 -0.7208038 2.1259505 H -3.6692421 0.45865293 .4355831 H -4.3975156 1.00861240 .7022845 H -4.0857235 2.2435374 1.9211062 H -2.2838352 2.54006870 .2911328 H -0.0873922 -0.7748739 2.8182276 H -1.6089754 -1.4932548 3.3446181 H $-0.9081800-0.16017204 .2650900$ H -4.1489911 $1.2460545-2.1011900$ H -3.3909731 $0.3853741-3.4447952$ H -2.4153203 $0.9335564-2.0698166$

\section{$1 \mathrm{Me}_{2}-\mathrm{A}_{\mathrm{HB}}$}

Energy $=-1518.481167024$

N -0.0765891 $6.4884801-1.4770264$

C - $0.02188165 .3568996-1.2223501$

C $0.05328733 .9943205-0.9148594$

C - $1.15362043 .3152410-0.7204831$

N -2.1455008 2.7321326 -0.5597769

C $1.31547653 .3117208-0.8129886$

C $2.53566733 .9773732-1.0393728$

C $3.74100873 .3181646-0.9398577$

C $3.78745401 .9574423-0.6254961$

C $2.58587811 .2812551-0.4000453$

C $1.38260481 .9446669-0.4831248$

H $0.46978491 .3963389-0.2878616$

H $2.59699080 .2313753-0.1313949$

C $5.05623801 .2512821-0.5299039$

N 6.08171161 .65859110 .1965679

C 7.23154310 .78030140 .0109397

C $6.6299887-0.3947761-0.7625978$

N $5.32255170 .1191937-1.1541782$

C $4.5030229-0.5858464-2.1099854$ 
C 6.14495672 .78748841 .0912720 H 5.14629383 .14329501 .3272516 H 6.72029883 .60472480 .6554810 H 6.62665062 .47854882 .0177791 H $4.65433623 .8663176-1.1355258$ H $2.53977305 .0278278-1.3014789$ N $0.6932111-5.91587051 .6459672$ C $0.6294981-4.79730751 .3408969$ C $0.5438515-3.45045200 .9726376$ C $1.7434110-2.78588520 .6993865$ N $2.7294606-2.21496340 .4726051$ C - $0.7208463-2.77016900 .8873329$ C - $0.8015359-1.42100770 .4927050$ C $-2.0074151-0.76014110 .4255459$ C -3.1987835 -1.4227272 0.7316269 C $-3.1393511-2.76640981 .1104003$ C -1.9308178 -3.4217352 1.1948038 H -1.9241870 -4.4579682 1.5082169 H -4.0440045 -3.3029554 1.3682776 C -4.4721187 -0.72272620 .6524790$ N -5.5241726 -1.1657187 -0.0124821

C -6.6691165 -0.28205040 .1774444$

C -6.04305390.9277753 0.8744748

N -4.7175730 0.43667851 .2335083

C -3.8623199 1.18700672 .1211766

C $-5.6178880-2.3336519-0.8528736$

H -6.1347219-2.0669449 -1.7735876

H -6.1744335 -3.1310054 -0.3597194

H -4.6278889 -2.6988333 -1.1099542

H -2.0294156 0.27525800 .1057723 H $0.1022552-0.88621600 .2293103$ H -3.07591890.5510694 2.5176352 H -4.4583367 1.55554812 .9545939 H -3.4094508 2.0316234 1.6027527 H $5.1317997-0.9164749-2.9352121$ H $3.73407360 .0704465-2.5075217$ H $4.0289053-1.4525991-1.6505671$ H -6.5880398 1.22633731 .7684207 H -5.9555056 1.79573260 .2183678 H -7.4270693 -0.77662810 .7874360$ H -7.1124607 -0.0297923-0.7845037 H $7.2104158-0.6582843-1.6451404$ H $6.5112732-1.2893315-0.1484149$ H $8.01299461 .2988291-0.5473649$ H 7.63753040 .48377490 .9767239

\section{$1 \mathrm{Me}_{2}-\mathrm{A}_{\mathrm{SD}}$}

Energy $=-1518.486353351$

N -8.3479444 5.5193354 7.4680938

C -8.4059864 4.47328936 .9678084

C - 8.46454163 .21153266 .3657155

C -9.7183693 2.7725762 5.9298471

N -10.7579564 2.39298315.5765975

C -7.2932039 2.3939752 6.2187238

C -6.0449363 2.79657856 .7321251 
C -4.9267508 2.00706566 .5954517 C -4.9909872 0.77278875 .9385164 C -6.2253061 0.36251505 .4246378 C -7.3444641 1.14942405 .5625493 H -8.2817591 0.79562395 .1541259 H -5.9531562 3.73732037 .2597606 H -3.9980078 2.3461547 7.0360551 H $-6.3107811-0.56939404 .8803473$ C -3.8095657 -0.06046385 .8083449$ N -2.6083901 0.38455635 .4738904 C -2.2205126 1.71202595 .0670262 C - $1.6114587-0.67203265 .6152565$ C -2.4816316 -1.9213495 5.6855760 N -3.7889265 -1.3674347 6.0229982 C -4.8482569 -2.2120045 6.5180717 N -3.6014561 -3.6424146 0.4431481 C -3.5448409 -2.5892244 0.9283815 C -3.4878612 -1.3190417 1.5127186 C -2.2332131 -0.8692927 1.9350022 N -1.1927372 -0.48142612 .2764989$ C -4.6612092 -0.50312851 .6529186$ C -5.9092294 -0.9150882 1.1462997 C -7.0291571 -0.1266902 1.2748040 C -6.9670868 1.11543281 .9170193 C -5.7332489 1.53454932 .4249536 C -4.6122115 0.74889892 .2948715 H -3.6754745 1.10966452 .6985755 H -5.9993290 -1.8620926 0.6297356 H -7.9575573 -0.47299900 .8391567$ H -5.6494603 2.47269992 .9586631 C -8.1501525 1.94756772 .0394078 N -8.1732253 3.2521554 1.8112617 C -7.11610474.0926857 1.3048105 C -9.4808892 3.80779032 .1441284 C - 10.34879312 .55793222 .2327186 N -9.3499480 1.50414832 .3804882 C -9.7359187 0.17965352 .7982871 H -6.6405743 4.66381632 .1031191 H -7.5394629 4.79255630 .5865216 H -6.3629778 3.49769080 .7962836 H -4.4274678 -2.9203487 7.2294986 H -5.3229291 -2.7738467 5.7125976 H -5.6018253 -1.6217416 7.0314260 H -2.1559900 -2.6215679 6.4522439 H -2.5344391 -2.4512351 4.7309215 H -1.0292602 -0.5126485 6.5259905 H $-0.9401300-0.67484364 .7601742$ H -9.8094625 4.4972667 1.3690166 H -9.4271496 4.3503999 3.0915161 H -10.9358761 2.3876500 1.3271357 H -11.01519972.5690746 3.0916504 H -1.7170944 2.2445079 5.8749024 H -3.0873568 2.28773404 .7551864 H - 1.53646221 .63265054 .2235534 H -8.8683834 -0.3923610 3.1150254 H -10.2383922 -0.3601111 1.9946912 H -10.4201900 0.26515143 .6409278 


\section{2-A}

Energy $=-1665.828220464$

N -2.7462028 2.2596892 -0.3833424

C $-1.79846312 .9125365-0.2324144$

C $-0.63920733 .6604964-0.0423220$

C - 0.79380705 .02773890 .2209316

N -0.9129596 6.16126710 .4359036

C $0.65354963 .0310352-0.0612524$

C $0.80018441 .6705004-0.3944434$

C $2.02976211 .0567488-0.3776436$

C $3.18451441 .7689642-0.0321120$

C 3.05500903 .12890680 .2754133

C 1.82463673 .74390110 .2596857

H 1.76701964 .79295610 .5199746

H 3.91717533 .71855380 .5615131

C 4.46615231 .11559310 .0127101

N $4.6761385-0.19598350 .1295753$

C $6.0305406-0.44877000 .1422010$

C $6.7493165-1.63096520 .2461927$

C $8.1287838-1.51999250 .2289299$

C $8.7653830-0.27698630 .1122733$

C 8.04706080 .90200280 .0094465

C 6.66524790 .78706660 .0285696

N $5.65641411 .7226874-0.0491018$

H $5.78898272 .7123533-0.1973651$

H $8.53883391 .8607574-0.0802039$

H $9.8460251-0.23744830 .1035452$

H $8.7309303-2.41497470 .3065125$

H $6.2585985-2.59046140 .3356619$

H $3.9475238-0.91334820 .2759914$

H $2.08977860 .0152550-0.6659650$

H $-0.06339061 .0875221-0.6889367$

N $0.9195439-6.1332839-0.2638303$

C $0.8000531-4.9998820-0.0482913$

C $0.6452178-3.63279310 .2156887$

C $1.8042005-2.88462160 .4068880$

N $2.7516614-2.23167970 .5589883$

C - $0.6476178-3.00362910 .2348781$

C $-1.8189629-3.7169581-0.0842061$

C $-3.0494031-3.1021431-0.0995562$

C $-3.1788776-1.74180310 .2064356$

C $-2.0238974-1.02927070 .5505009$

C - $0.7942324-1.64274230 .5668661$

H $0.0695557-1.05924440 .8596024$

H -2.0835873 0.01260510 .8375423

C - $4.4604057-1.08822340 .1614435$

N -5.6508700 -1.6952033 0.2196907

C - $6.6594580-0.75904640 .1433199$

C - $8.0413076-0.87357960 .1599621$

C - 8.75911760 .30589580 .0597415

C -8.1220940 $1.5491061-0.0518933$

C - $6.74247911 .6597628-0.0667972$

C -6.02422680 .47694520 .0343822$

N -4.6699319 $0.2237807 \quad 0.0481155$ 
H -3.9410755 $0.9415369-0.0953260$ H -6.2514642 2.6194128 -0.1524558 H -8.7238257 $2.4445581-0.1273541$ H -9.8398491 0.26659460 .0665870 H -8.5334808 -1.83255300 .2458432$ H -5.7838766 -2.6854127 0.3638589 H -3.9116551 -3.6924737 -0.3839884 H -1.7615349 -4.7663098 -0.3432764

\section{2-A}

Energy $=-1665.823730518$

N -6.6343463 5.2138048 5.4517987

C -6.6281864 4.06227245.5916506

C -6.5984293 2.67192435 .7600777

C -7.7284585 2.06968736 .3280157

N -8.6555370 1.55855686 .8022480

C -5.4499561 1.90413905 .3938406

C -4.31046712 .50951864 .8221472$

C -3.2129489 1.76971804 .4616269

C -3.1774422 0.38100094 .6516269

C - $4.3047272-0.22875595 .2204314$

C -5.40557770 .50603835 .5813352$

H -6.2527780 -0.00891086 .0156060$

H -4.2919874 3.57877504 .6554261

H -2.3746281 2.2962719 4.0232658

H -4.3377679 -1.2979625 5.3874815

C - $2.0295615-0.38861964 .2759022$

N -0.90098820 .08324473 .7336206$

H -0.7285689 1.05394433 .5224292

C $0.0051156-0.93971043 .5465482$

C - $0.6243245-2.09799003 .9955520$

N -1.8750117 -1.70907874.4276780

H -2.5627013 -2.3245565 4.8336983

N -1.9309027 -4.2558541 1.2152407

C - $1.9364817-3.10620101 .0606327$

C - $1.9649997-1.71801820 .8746964$

C $-0.8382840-1.12512720 .2905436$

N $0.0855399-0.6216264-0.1979788$

C -3.1096455 -0.94332581 .2383015$

C -4.2494292 -1.5399268 1.8183657

C -5.3435651 -0.79348372 .1753528$

C -5.3749466 0.59364771 .9736959

C -4.2468767 1.19504541 .3974689

C -3.1495390 0.45340641 .0397635

H -2.3017876 0.96187330 .5987516

H -4.2705476 -2.6075723 1.9952269

H -6.1812994 -1.3127174 2.6232841

H -4.2114166 2.26237681 .2191921

C -6.5193737 1.36997662 .3461378

N -6.6571613 2.6942455 2.2131807

H -5.9542781 3.30859381 .8324098

C -7.9087540 3.09085232 .6356170

C -8.5569191 1.93290433 .0580640

N -7.6601990 0.90261042 .8663135

H -7.8495886 -0.0699684 3.0528867 
C $1.2924083-0.95779123 .0366511$ C $1.9235411-2.18974043 .0011629$ C $1.2909891-3.35391093 .4532033$ C $0.0018306-3.33244463 .9581211$ H -0.4900000 -4.2315142 4.3012822 H $1.7775631-0.05956492 .6821201$ H $2.9305872-2.25447142 .6122415$ H $1.8219835-4.29480613 .4045628$ C -8.5211453 4.3317458 2.6858497 C - 9.81598854 .35998603 .1755200 C - 10.46767953 .19600353 .5997453 C - 9.85034411 .95753083 .5518107 H -10.3502499 1.05915153 .8848890 H -8.0146618 5.2305976 2.3641365 H -10.3364979 5.3062567 3.2337566 H -11.47881213.2660684 3.9770834

\section{2-A}

Energy $=-1665.820686209$

N -6.2224683 4.70233874.4755463

C -6.2353716 3.56854044 .7300355

C -6.2682396 2.1946527 4.9861714

C -7.5360787 1.62225695 .1518845

$\mathrm{N}-8.58636651 .14471715 .2759943$

C -5.0833418 1.39003144 .9400441

C -3.8085016 1.96446294 .7666707

C -2.68039431 .18680174 .6784064$

C $-2.7588712-0.20988434 .7633728$

C $-4.0214391-0.78811684 .9515706$

C $-5.1488564-0.01285585 .0458644$

H -6.1042249 -0.5019026 5.1815689

H -3.7051850 3.03872414 .6828810

H -1.7315492 1.68441324 .5214076

H -4.1366459-1.8615766 5.0345132

C - $1.5889958-1.02597144 .6267208$

N -0.3203264 -0.6061520 4.6473416

$\mathrm{H}-0.03513740 .34831904 .8063620$

C $0.5365751-1.66632694 .4464805$

C - $0.2705507-2.79352074 .3098710$

N - $1.5688834-2.35036294 .4376174$

H -2.3865750 -2.9353317 4.3438972

N -3.3167394 -4.2102381 2.1442712

C -3.3047028 -3.0780208 1.8828051

C -3.2745212 -1.7054541 1.6195730

C - $2.0081334-1.13187241 .4470622$

N -0.9588086 -0.65392541 .3167451$

C -4.4610212 -0.9034018 1.6669529

C -5.7334230 -1.4814015 1.8465177

C -6.8636302 -0.70706431 .9349844$

C - 6.78999430 .68945221 .8439403

C -5.5299582 1.27149031 .6510298

C -4.4001588 0.49944441 .5565623

H -3.4466566 0.99091331 .4162141

H -5.8329105 -2.5556494 1.9352214

H -7.8103655 -1.2064869 2.0986340 
H -5.4195527 2.34507381 .5629648 C -7.9638311 1.50012501 .9784245 N -7.99191562.82301552.1769138 H -7.1774897 3.41088672 .2803919 C -9.2935807 3.25818562 .3004387 C -10.09377342.12775242.1501719 N -9.2300015 1.07384511 .9463176 H -9.5088093 0.11948371 .7754537 C $0.2609859-4.05304564 .0848808$ C $1.6415013-4.13585784 .0113536$ C $2.4541015-3.00469654 .1573509$ C $1.9181512-1.74652124 .3771670$ H $2.5459260-0.87317634 .4874688$ H - $0.3683847-4.92498883 .9715476$ H $2.1034171-5.09801323 .8372239$ H $3.5279842-3.11606154 .0955624$ C -11.4761832 2.1995625 2.2119357 C - 12.02056313 .45255812 .4403003 C - 11.21507994 .58684552 .6006142 C -9.8337621 4.5126166 2.5331315 H -9.21042495.38746482.6567209 H -12.0983673 1.32376012 .0899323 H -13.0953793 3.55716442 .4977785 H -11.6830971 5.54480962 .7813393

\section{$2-\mathrm{S}_{\mathrm{HT}}$}

Energy $=-1665.809602873$

N -3.3589988 $2.5871210-0.6049024$

C - $2.38633123 .1926286-0.4195468$

C - $1.21120633 .9216022-0.1962177$

C -1.3430180 $5.3099199-0.0672563$

N -1.4452409 6.46079420 .0416862

C $0.06297303 .2791375-0.0997274$

C $0.19348371 .8793174-0.2188681$

C $1.41631341 .2641380-0.1228689$

C 2.58621212 .00568460 .0980300

C 2.46705143 .39836240 .2154909

C 1.24570334 .01667610 .1196265

H 1.20237775 .09378680 .2164923

H 3.33487014 .02317340 .3851591

C 3.86167071 .36042970 .2039490

N 4.09388900 .04641810 .1137190

C $5.4389766-0.21182630 .2681223$

C $6.1654171-1.39187290 .2568014$

C $7.5320389-1.27694370 .4492073$

C $8.1454475-0.03328350 .6452241$

C 7.41632321 .14403470 .6551541

C 6.04918911 .02531060 .4621726

N 5.03806401 .96088400 .4139640

H 5.16615612 .95576550 .5224412

H 7.88896952 .10477910 .8055379

H 9.21581520 .00911330 .7930102

H $8.1409169-2.17056880 .4480442$

H $5.6906291-2.35151830 .1062091$

H $3.3856647-0.6546411-0.0438683$ 
H $1.44635720 .1864907-0.2233321$

H -0.6820241 $1.2659442-0.3882119$

N -16.5918670 8.6555116 -1.9241511

C - $15.68925459 .3518121-1.7081259$

C - $14.592213510 .1836520-1.4477766$

C - $14.850260711 .5556954-1.3281014$

N -15.0557996 $12.6931562-1.2271019$

C -13.2698217 $9.6561761-1.3097507$

C -13.0103505 8.2735559-1.4245478

C $-11.74063047 .7698035-1.2915488$

C - $10.64860148 .6120650-1.0353317$

C -10.8961107 $9.9879971-0.9196713$

C - $12.164429210 .4950873-1.0523511$

H $-12.306224611 .5636286-0.9556365$

H -10.0932108 $10.6875747-0.7239590$

C -9.3234130 8.0845996-0.8953052

$\mathrm{N}-8.96638346 .7996063-0.9975145$

C -7.6083615 $6.6650725-0.8032686$

C $-6.77370025 .5588549-0.8093179$

C $-5.43070515 .7983758-0.5712938$

C $-4.94289527 .0899596-0.3367317$

C $-5.78008258 .1927246-0.3321214$

C -7.1232286 $7.9500232-0.5706612$

N -8.2153575 8.7878779 -0.6374410

H -8.1845078 $9.7877480-0.5065514$

H -5.4045421 $9.1905267-0.1521312$

H -3.8859058 $7.2292073-0.1550505$

H -4.7422242 4.9641884 -0.5671551

H -7.1517620 $4.5621572-0.9901853$

H -9.6000535 $6.0387511-1.1915832$

H -11.6113657 6.6993230-1.3901829

H -13.8213588 $7.5841936-1.6206364$

\section{$2-\mathrm{S}_{\mathrm{ST}}$}

Energy $=-1665.821415525$

N -3.2939944 2.5678611 -0.8295765

C -2.3359354 $3.1657566-0.5656919$

C - $1.16791633 .8802762-0.2645988$

C - $1.29494625 .2693934-0.1270339$

N -1.3922848 $6.4208598-0.0286248$

C $0.08413613 .2234747-0.1031597$

C $0.21023321 .8231903-0.2559558$

C $1.42214401 .1950733-0.1321344$

C 2.59096051 .91651040 .1632568

C 2.47201633 .30526620 .3399249

C 1.26290603 .93818710 .2098132

H 1.22126035 .01028110 .3512374

H 3.33751563 .91487170 .5681626

C 3.85445211 .25804160 .2819688

N $4.1078122-0.02816480 .0068820$

C $5.4355225-0.31501260 .2447589$

C $6.1659822-1.48725580 .1392327$

C $7.5046897-1.41520860 .4888127$

C $8.0871792-0.21893010 .9239541$

C 7.35330350 .95120221 .0272855 
C 6.01529360 .87400030 .6793703 N 5.00453281 .81126850 .6867704 H 5.11264492 .77375430 .9675192 H 7.80111931 .87424661 .3681160 H $9.1359386-0.20814351 .1874419$ H $8.1145254-2.30587680 .4243161$ H $5.7155003-2.4112602-0.1959097$ H $3.4331871-0.6798957-0.3636649$ H $1.44720890 .1199549-0.2621102$ H -0.6632086 $1.2240983-0.4776086$ N -6.0684736 3.14735721 .7957494 C - 5.15476233 .80423852 .0780320 C - 4.05697304 .59951382 .4325020 C - 4.27026735 .98357282 .4754666 N -4.4500270 7.12911382 .5185354 C -2.78054034 .03016272 .7252713$ C - 2.56283342 .63739802 .6655367 C - 1.32424352 .09880862 .8983101

C -0.22838382 .91396143 .2182492$ C - 0.44270084 .29702623 .3103887 C - 1.67924404 .83874013 .0770142 H -1.79441695.9127173 3.1344570 H 0.36762804 .97407473 .5499477 C 1.07736292 .36145953 .3901200 N 1.42969621 .08350943 .1994851 C 2.77836920 .91929033 .4293212 C $3.6079423-0.18826103 .3462605$ C 4.94393270 .01434423 .6502477 C 5.42857581 .27269344 .0255643 C 4.59899082 .37919044 .1006380 C 3.26347572 .17425113 .7908558 N 2.18112473 .02662883 .7542343 H 2.20860004 .00615963 .9926713 H 4.97454773 .35218104 .3859234 H 6.47909711 .38513144 .2554016 H $5.6295492-0.82012853 .5937049$ H 3.2326430 -1.1613479 3.0608285 H 0.79646640 .35197062 .9159818 H -1.2190710 1.02364622 .8244235 H -3.3774068 1.97454052 .4058942

\section{$2 \mathrm{Me}-\mathrm{A}_{\mathrm{HB}}$}

Energy $=-1744.271789856$

N -0.6033831 6.0922074-1.2022245

C - $0.45839055 .0376851-0.7408307$

C - $0.26931873 .7667336-0.1833214$

C - 1.39178063 .12348880 .3292087

N -2.3147582 2.56348490 .7576709

C $1.02211253 .1296518-0.1695218$

C $2.14274313 .7305377-0.7708653$

C $3.37586363 .1179900-0.7648886$

C $3.55541461 .8718223-0.1539665$

C 2.44525431 .26232350 .4435516

C 1.21394691 .87516370 .4393697

H 0.38710371 .37504420 .9276786 
H 2.54769270 .30752770 .9427998 C $4.82647631 .1834222-0.1718320$ N $6.04824971 .7250514-0.0608448$ C $6.98990320 .7154590-0.1407909$ C $6.2850820-0.4770435-0.2829508$ C $6.9300514-1.7017257-0.3848551$ C $8.3122753-1.6780379-0.3370974$ C $9.0222195-0.4782054-0.1929495$ C $8.37670430 .7420265-0.0928158$ H 8.93412721 .66292100 .0114362 H $10.1028027-0.5058340-0.1621297$ H $8.8593922-2.6077298-0.4135849$ H $6.3808484-2.6266176-0.4959414$ N $4.9545493-0.1376249-0.2994202$ H $4.1757020-0.8009479-0.4518854$ C 6.37561513 .11209240 .2074634 H 5.55473593 .59223230 .7310161 H $6.58767593 .6488511-0.7143989$ H 7.25184283 .14598900 .8493903 H $4.19387863 .6060758-1.2777006$ H $2.04483004 .6876465-1.2667752$ N $1.1809503-5.56780521 .3468211$ C $1.0375254-4.51411260 .8830474$ C $0.8504501-3.24416600 .3226740$ C $1.9740438-2.6027099-0.1897229$ N $2.8974779-2.0438512-0.6186118$ C - $0.4404913-2.60624370 .3045192$ C $-0.6292661-1.3519040-0.3055763$ C $-1.8601141-0.7382921-0.3146814$ C - $2.9729124-1.34707320 .2785529$ C - $2.7964043-2.59283410 .8910681$ C - $1.5636156-3.20599220 .9024109$ H -1.4680222 -4.1627199 1.3994909 H -3.6168303 -3.0801798 1.4008260 C -4.2441030 -0.65875490 .2898921$ N -5.4649336 -1.2004220 0.1702266 C -6.4072390 -0.19112250 .2452177$ C -5.7036845 1.00140080 .3937387 C -6.3496030 2.22566640 .4930978 C -7.7314835 2.2018030 0.4359244 C -8.4401649 1.00198290 .2852041 C -7.7937367 -0.21791640 .1876896$ H -8.3500279 -1.13891550.0783595 H -9.5205375 1.02946940 .2473951 H -8.2793123 3.13119990 .5103297 H -5.8014668 3.15061480 .6092815 N -4.3731414 0.66206470 .4186970 H -3.5948531 1.32488510 .5761797 C $-5.7898438-2.5871993-0.1025082$ H $-6.6607764-2.6204408-0.7516106$ H $-6.0092050-3.12519540 .8169405$ H -4.9644752 -3.0664703 -0.6197490 H -1.9600175 $0.2164132-0.8146090$ H $0.1997291-0.8524104-0.7908382$ 


\section{Me-A}

Energy $=-1744.260370506$

N -8.0466849 5.0457515 6.1320991

C -8.0306340 3.88646156 .1670467

C -7.9945826 2.48653966 .2023505

C -9.1801068 1.82032606 .5327298

N -10.1514840 1.24997286 .8129212

C -6.7970602 1.76157845 .9057166

C - 5.56152922 .41588205 .7225898

C - 4.41028991 .71140455 .4721849

C - 4.41760430 .31142525 .3688477

C - $5.6505350-0.34259265 .4977727$

C - 6.80066810 .35766955 .7714129

H -7.7263286 -0.19528275 .8765389$

H -5.5016282 3.49315885 .8090418

H -3.4836816 2.26603615.3921684

H -5.7330506 -1.4101229 5.3527877

C - $3.1859113-0.39074215 .1253158$

N -2.11885380 .15587134 .5301935$

H -2.1213018 1.07075374 .1047729

C - $1.0899645-0.75321124 .4610964$

C - $1.5732999-1.91645265 .0502129$

N -2.8675176-1.6494863 5.4665128

C - $3.6444906-2.57086536 .2741275$

N $-2.3575321-3.36200781 .4274080$

C $-2.3729606-2.20279371 .3893440$

C - $2.4070387-0.80296091 .3500635$

C - $1.2214986-0.13928701 .0144091$

N -0.25094550 .43006330 .7294170$

C - $3.6027338-0.07457841 .6456298$

C $-4.8399845-0.72488681 .8314873$

C - $5.9890725-0.01622792 .0803103$

C - 5.97770751 .38404652 .1794507

C - 4.74297412 .03417882 .0477987

C -3.5951347 1.32973471 .7756634

H -2.6678362 1.87953461 .6685443

H -4.9030966 - 1.80230911 .7486522

H -6.9172402 -0.5679077 2.1626289

H -4.6571294 3.10188942 .1894698

C -7.2072120 2.09042542 .4217351

N -7.52238483 .34917852 .0774608$

C -6.7431495 4.26612551 .2669445

C -8.81584003 .62060222 .4934578$

C -9.3019865 2.46012323 .0857141

N -8.2754536 1.54824483 .0187714

H -8.2752373 0.63453043 .4466918

C $0.1960048-0.66776613 .9519997$

C $0.9754193-1.80645394 .0512994$

C $0.4893895-2.98037614 .6395733$

C - $0.7944296-3.05929615 .1505196$

H -1.1621200 -3.9723166 5.5981594

H 0.56666210 .23604513 .4905592

H 1.9854531 -1.7892655 3.6651737

H $1.1322130-3.84820454 .6954469$

C -9.5920914 4.7650142 2.3900810

C - 10.87616424 .69044262 .9011055 
C - 11.36500653 .51923483 .4924590

C -10.58819372.3790489 3.5949258

H -10.96101171 .47724184 .0585608$

H -9.2224144 5.6759779 1.9398517

H -11.5170669 5.55953272 .8424884

H -12.3751973 3.50533753 .8783376

H -6.1069542 4.8973248 1.8836701

H -7.4259043 4.89725180 .7053615

H -6.1373056 3.71388160 .5549786

H -2.9602094 -3.2003373 6.8357391

H -4.2771392 -3.2033316 5.6550544

H -4.2537869 -2.0223891 6.9860326

\section{Me-A}

Energy $=-1744.266136660$

N -4.64495912.5940803 5.6089002

C -4.6568995 1.45582905 .3833882

C -4.6781160 0.0825016 5.1069537

C -5.9438211 -0.48492014 .9838360$

$\mathrm{N}-7.0204003-0.91287094 .8685956$

C -3.4734715 - 0.65467074 .8525531

C - $2.2147926-0.02729994 .9005257$

C $-1.0597598-0.72288454 .6379570$

C - $1.0974736-2.08922934 .3347279$

C - $2.3436906-2.72621214 .2893804$

C -3.4999611 -2.0267093 4.5410768

H -4.4464165 -2.5474816 4.4722467

H -2.1437252 1.02617895 .1383497

H -0.1126105 -0.2008701 4.6910937

H -2.4205863 -3.7682759 4.0081888

C $0.1243986-2.77432713 .9973197$

N $1.1150968-2.22222363 .2898042$

H $1.0260607-1.32375272 .8134173$

C $2.1343108-3.13038273 .1240912$

C $1.7266166-4.28895823 .7806804$

N $0.4799480-4.02478074 .3204014$

C - $0.2384918-4.94173515 .1836948$

N -2.2354070 -3.5451941 0.7003852

C - $2.2121879-2.40837340 .9319330$

C - $2.1792960-1.03653641 .2145737$

C -0.9096686 -0.47836241 .3383851$

N $0.1690409-0.05588711 .4540052$

C -3.3780761 -0.2911409 1.4725003

C -4.6416559-0.9085491 1.4238317

C -5.7907218 -0.20542751 .6925212$

C -5.7418457 1.15885562 .0033550

C -4.4906632 1.78635772 .0472872

C -3.3405661 1.07954651 .7887757

H -2.3900964 1.59298231 .8570867

H -4.7214035 -1.9602503 1.1809558

H -6.7418447 -0.7201161 1.6389957

H -4.4047427 2.82621902 .3337112

C -6.9560982 1.85029492 .3539306

N -7.3011663 3.10847432 .0497256

C -6.5790805 4.02938801 .1935992 
C - 8.54257243 .37736512 .5993332

C -8.9585582 2.2138859 3.2418356

N -7.94901121 .29828793 .0586162$

H -7.8689490 0.39146293 .5195302

C $3.3523291-3.05230642 .4657687$

C $4.1465697-4.18528582 .4982845$

C $3.7400099-5.34892193 .1637237$

C $2.5217143-5.42500383 .8169880$

H $2.2123469-6.32964614 .3223884$

H $3.6663719-2.15333661 .9536615$

H $5.1052473-4.17192251 .9980764$

H $4.3925255-6.21122213 .1646443$

C - 9.32634784 .52167492 .5830567

C - 10.54215144 .44853933 .2413154

C - 10.95707283 .27979543 .8924195

C - 10.17409602 .13857943 .9049744

H -10.4946348 1.23566854 .4059986

H -9.0104343 5.43027472 .0889274

H -11.18601195.3171990 3.2556490

H -11.9132498 3.26900824 .3974490

H -5.9880882 4.7272172 1.7827009

H -7.2942491 4.58530070 .5930432

H -5.9289683 3.47605050 .5230373

H $0.4778368-5.48001435 .7987917$

H $-0.8155219-5.65511134 .5994472$

H -0.9014705 -4.3866749 5.8400583

\section{$2 \mathrm{Me}-\mathrm{S}_{\mathrm{HT}}$}

Energy $=-1744.252759375$

N $18.28392801 .3582675-3.5592668$

C $17.76483820 .8230721-2.6696014$

C $17.12973630 .1802128-1.6001862$

C $17.9512385-0.4696776-0.6711555$

N $18.6246986-1.01150890 .1036136$

C $15.70209500 .1845271-1.4635298$

C $14.87378250 .8291455-2.4044682$

C $13.50532500 .8388369-2.2704795$

C $12.88459420 .2007616-1.1888291$

C $13.6964506-0.4565828-0.2540544$

C $15.0645475-0.4597344-0.3833047$

H $15.6540720-0.96528180 .3707746$

H $13.2567141-0.94899600 .6046714$

C $11.45124010 .1566520-1.0453413$

N $10.56593731 .1173624-1.3385725$

C $9.29124650 .6521748-1.0651423$

C $9.4321040-0.6379374-0.5619958$

C $8.3392869-1.3987893-0.1760419$

C $7.0957439-0.8088477-0.3178786$

C $6.95143210 .4890310-0.8249912$

C $8.04536321 .2458311-1.2079976$

H $7.92423702 .2448059-1.6039271$

H $5.96014810 .9085889-0.9272885$

H $6.2136033-1.3629484-0.0274689$

H $8.4532469-2.40022790 .2151791$

N $10.7820412-0.8977609-0.5685338$ 
H $11.2112092-1.7833822-0.3420384$ C $10.85367782 .4736215-1.7649244$ H $10.78999822 .5637112-2.8469089$ H $11.84476032 .7635225-1.4299970$ H $10.13118323 .1438869-1.3071125$ H $12.91654841 .3179578-3.0413610$ H $15.31101791 .3232460-3.2625522$ N $3.8134984-1.64658941 .2947592$ C $3.2002121-1.34049510 .3575835$ C $2.4566383-0.9744489-0.7704057$ C $3.1707756-0.4531660-1.8560949$ N $3.7585930-0.0187743-2.7579363$ C $1.0307790-1.1220823-0.8083909$ C $0.2827937-0.7635861-1.9487141$ C - $1.0839257-0.9045242-1.9819945$ C $-1.7826564-1.4231761-0.8830605$ C - $1.0519458-1.77593340 .2589713$ C $0.3144399-1.62787340 .2952326$ H $0.8384121-1.89957821 .2026175$ H - $1.5538190-2.13517691 .1476245$ C $-3.2189975-1.5290102-0.9342753$ N $-3.9905967-2.4832124-0.3989399$ C $-5.3166975-2.1913653-0.6673449$ C $-5.3277110-1.0203565-1.4199257$ C $-6.5077867-0.4457827-1.8666827$ C -7.6794594 -1.0984517-1.5258482 C $-7.6704595-2.2782328-0.7705160$ C $-6.4899734-2.8480680-0.3255429$ H $-6.4929358-3.75563280 .2623678$ H -8.6097498 -2.7547532 -0.5255784 H -8.6256481 -0.6871661 -1.8497759 H -6.5121554 $0.4647230-2.4496088$ N -4.0106239 -0.6516472 -1.5591417 H -3.6809977 $0.2034539-1.9834327$ C -3.5500535 -3.6971950 0.2617056 H $-4.2271430-4.5046923-0.0032016$ H -3.5467637 -3.5733248 1.3421790 H -2.5549699 -3.9637723 -0.0807901 H -1.6104907 -0.6338342-2.8891560 H $0.7842820-0.3746953-2.8256923$

\section{$2 \mathrm{Me}-\mathrm{S}_{\mathrm{ST}}$}

Energy $=-1744.261031304$

N $4.97390453 .6369185-2.0420270$

C $4.65570753 .1570749-1.0348210$

C 4.27357522 .59989510 .1924339

C 5.29337712 .37194221 .1246161

N 6.13705912 .18622951 .8998775

C 2.91081792 .28386970 .4843045

C $1.89003072 .4593045-0.4716252$

C $0.58378262 .1429814-0.1947149$

C 0.21095401 .64012311 .0612773

C 1.22264901 .46573442 .0205363

C 2.52772981 .77947741 .7446711

H 3.27102341 .63062542 .5166333 
H 0.98602221 .10345033 .0136176 C -1.1229169 1.2070057 1.3612721 N -2.2833761 1.61971870 .8229912 C -3.3223065 0.88246681 .3672421 C - 2.75733100 .01134832 .2940232 C -3.5229603 -0.89172813 .0148939$ C -4.8858182 -0.88313862 .7676866$ C -5.4578434 -0.0002093 1.8451831 C -4.6885136 0.90172921 .1292824 H -5.1425846 1.57721290 .4170533 H -6.5260180 -0.0276344 1.6793138 H -5.5224721 -1.57566003 .3009574$ H -3.0798283 -1.56683863 .7339344$ N -1.4064683 0.25938332 .2652779 H $-0.7069580-0.26854012 .7644916$ C -2.4850873 2.7269760 -0.0904841 H -2.4408337 2.3999733 -1.1280338 H -1.7359394 3.49413220 .0802899 H -3.4613742 3.16376970 .1001093 H -0.1383865 2.2440002 -0.9915086 H $2.13640992 .8168940-1.4625942$ N $3.9139087-1.61255361 .2385399$ C $3.2839610-1.28782180 .3203512$ C $2.5196586-0.9103569-0.7912816$ C $3.1942992-0.2722005-1.8412355$ N $3.74021700 .2392666-2.7275285$ C $1.1133919-1.1288769-0.8421046$ C $0.3372260-0.6876363-1.9377442$ C $-1.0206488-0.8683356-1.9731195$ C $-1.7029188-1.5159012-0.9265396$ C - $0.9347987-1.98222600 .1531954$ C $0.4241694-1.79272850 .1954120$ H $0.9682053-2.15374131 .0588818$ H -1.4009365 -2.4672084 0.9988502 C $-3.1358090-1.6100205-0.9696501$ N $-3.9398440-2.4990345-0.3662286$ C $-5.2586762-2.1848857-0.6509159$ C $-5.2386965-1.0747025-1.4878538$ C $-6.4017631-0.4797202-1.9487139$ C $-7.5929921-1.0509692-1.5341565$ C $-7.6158730-2.1724991-0.6967500$ C $-6.4494581-2.7614979-0.2379607$ H -6.4791939 -3.6189283 0.4200572 H -8.5681786 -2.5865038 -0.3950829 H -8.5279160 -0.6194303-1.8642878 H $-6.38140040 .3873730-2.5943404$ N $-3.9118318-0.7580564-1.6575224$ H -3.5626794 $0.0193474-2.1964959$ C -3.5478104 -3.6800982 0.3774293 H -4.3125693 -4.4406437 0.2488072 H -3.4451491 -3.4599906 1.4383514 H -2.6148926 -4.0757489-0.0122346 H $-1.5545213-0.5236254-2.8505047$ H $0.8142127-0.1880000-2.7706740$ 


\section{$2 \mathrm{Me}_{2}-\mathrm{A}_{\mathrm{HB}}$}

Energy $=-1822.701938228$

N $-0.05954956 .5009381-1.4453040$

C $-0.01213695 .3667178-1.2024580$

C $0.05753964 .0001817-0.9091305$

C - $1.15089453 .3231137-0.7180328$

N -2.1434222 2.7408461 -0.5590870

C $1.31660963 .3143710-0.8113317$

C $2.53942283 .9805292-1.0239710$

C $3.74259753 .3189513-0.9276617$

C $3.78798481 .9543429-0.6219045$

C $2.58158301 .2785283-0.4089071$

C $1.38040901 .9429297-0.4977063$

H $0.46576421 .3931694-0.3160271$

H $2.58761640 .2279413-0.1432813$

C $5.04954741 .2505442-0.5239350$

N 6.11306271 .65045380 .1853409

C 7.12091030 .71993170 .0423978

C $6.6200761-0.2851952-0.7782190$

C $7.3775858-1.3970837-1.1186977$

C $8.6591461-1.4540353-0.6004464$

C $9.1640476-0.44084670 .2254476$

C 8.40648540 .66679160 .5624500

H 8.80480831 .44761411 .1957791

H $10.1717517-0.52634690 .6081581$

H $9.2862748-2.3024185-0.8375929$

H $6.9918594-2.1849518-1.7510907$

N $5.33726670 .0872900-1.1205828$

C $4.5032673-0.6450183-2.0559756$

C 6.20030242 .81544991 .0445847

H 5.20433023 .13557021 .3334839

H 6.71226273 .63066270 .5384975

H 6.74928992 .54901881 .9439718

H $4.65595193 .8677570-1.1201358$

H $2.54684515 .0333474-1.2756664$

N $0.6837840-5.92182911 .6146446$

C $0.6254570-4.80061621 .3194149$

C $0.5431008-3.44974910 .9633701$

C $1.7434609-2.78364650 .6977820$

N $2.7299168-2.21126770 .4773792$

C $-0.7197998-2.76896770 .8803140$

C $-0.7992388-1.41502750 .5006222$

C $-2.0045580-0.75553650 .4290097$

C - $3.1996466-1.42038660 .7242767$

C - $3.1389913-2.76850581 .0936822$

C - $1.9315724-3.42412401 .1742926$

H $-1.9265627-4.46316371 .4778335$

H -4.0428146 -3.30771261 .3484495$

C - $4.4671165-0.72457820 .6467211$

N -5.5566899 -1.15901060 .0004405$

C $-6.5641290-0.22887160 .1479488$

C -6.03610270 .81209130 .9043658$

C -6.7872934 1.93213091 .2318905

C -8.0905343 1.95947690 .7682434

C -8.6225909 0.91041680 .0067403

C -7.8712184-0.2050939-0.3178201 
H -8.2899131 -1.0136936-0.9011642

H -9.6466091 $0.9737495-0.3348889$

H -8.7138763 2.81263570 .9981350

H -6.38123392.7478039 1.8143658

N -4.7369198 0.46131771 .2059079

C -3.8663786 1.23718782 .0701593

C $-5.6718500-2.3588155-0.8059575$

H $-6.2543653-2.1307657-1.6947786$

H -6.1621966 -3.1531588 -0.2478847

H -4.6860873 -2.6889459-1.1176799

H -2.0235946 0.28064670 .1117826

H $0.1056908-0.87661660 .2494736$

H -3.1171474 0.58811892 .5127387

H -4.4625720 1.66861822 .8700054

H -3.3769540 2.02721551 .5052641

H $5.1314268-1.0355234-2.8524257$

H $3.77021620 .0248356-2.4945206$

H $3.9943709-1.4621846-1.5502501$

\section{$2 \mathrm{Me}_{2}-\mathrm{A}_{\mathrm{SD}}$}

Energy $=-1822.701444040$

N -4.2469347 -0.5534517 5.7562753

C - $4.3415644-1.45273945 .0279234$

C - $4.4429335-2.53875584 .1531457$

C -5.7270136 -2.9178289 3.7529928

N -6.7891518 -3.26396823 .4349631$

C -3.2816812 -3.2283473 3.6727355

C $-1.9943373-2.94088824 .1669908$

C $-0.8883345-3.63236003 .7324792$

C - $1.0052653-4.64881632 .7762662$

C - $2.2783830-4.92585102 .2590739$

C -3.3825364 -4.2354885 2.6931422

H -4.3433981 -4.4618217 2.2495507

H -1.8632675 -2.1754352 4.9212839

H $0.0734852-3.40062814 .1717585$

H -2.4028442 -5.66540811 .4787321$

C $0.1444976-5.40743432 .3434655$

N $1.3470166-4.90757682 .0243479$

C $1.7285223-3.50985201 .9702259$

C $2.1830694-5.94287571 .6627883$

C 1.4345509 -7.1109228 1.7558267

N $0.1806320-6.74137162 .1950756$

C - $0.8604002-7.68818802 .5458298$

N $-2.9840438-3.6665007-1.1574765$

C $-2.8869817-2.7689569-0.4272543$

C - $2.7832708-1.68513480 .4500010$

C - $1.4982696-1.31026970 .8513243$

N -0.4348187 -0.96833781 .1694730$

C $-3.9431089-0.99486870 .9322418$

C - $5.2305068-1.27682160 .4348090$

C - $6.3359159-0.58737510 .8736335$

C -6.2188038 0.42156771 .8379870

C -4.9452336 0.69464942 .3564123

C -3.8414665 0.00682131 .9173627

H -2.8805398 0.22954752 .3626341 
H $-5.3619329-2.0367283-0.3250066$

H -7.2974028 -0.81508010 .4317022$

H -4.8198391 1.42780653 .1425633

C -7.3693255 1.17390792 .2791932

N -7.4065947 2.50553722 .4474945

C -6.3657007 3.45837392 .1130433

C -8.6618196 2.86779552 .8893485

C -9.4099929 1.69818312 .9626773

N -8.5724933 0.66876802 .5881279

C -8.9538522 -0.72971512 .6212866$

C $3.5098628-5.95510361 .2575449$

C $4.0512343-7.19054650 .9469176$

C $3.2968421-8.36688831 .0387478$

C $1.9734652-8.35082261 .4442683$

H $1.3950973-9.26238091 .5067159$

H $4.0991198-5.05098721 .1887261$

H $5.0823405-7.24881460 .6263292$

H $3.7589567-9.31096020 .7847706$

C -9.20211194 .10246243 .2187625$

C - 10.52663164 .11176763 .6206183

C -11.2809276 2.93396733 .6917771

C -10.7380297 1.70366803 .3639287

H -11.3272033 0.79840263 .4171022

H -8.62399195.01514993.1721885

H -10.98981245.0516710 3.8879640

H -12.3130800 2.98693924 .0098358

H -5.7883356 3.73149292 .9933717

H -6.8285985 4.34957221 .6972761

H -5.7054433 3.03434471 .3631087

H -0.3978894 -8.5718806 2.9777732

H -1.4372089 -7.9767828 1.6701216

H -1.5212160 -7.2509017 3.2875652

H $2.3699008-3.35595441 .1060558$

H $2.2674579-3.22348312 .8712494$

H $0.8485987-2.88392341 .8579775$

H -8.0748616 -1.3567668 2.7344697

H -9.4845238 -1.0053757 1.7120900

H -9.6030550 -0.8943847 3.4775926 


\section{References}

[1] P. Rietsch, F. Witte, S. Sobottka, G. Germer, A. Becker, A. Güttler, B. Sarkar, B. Paulus, U. Resch-Genger, S. Eigler, Angew. Chem. Int. Ed. 2019, 58, 8235-8239.

[2] C. Reichardt, Chem. Rev. 1994, 94, 2319-2358.

[3] S. Grimme, C. Bannwarth, P. Shushkov, J. Chem. Theory Comput. 2017, 13, 1989-2009.

[4] P. Pracht, F. Bohle, S. Grimme, Phys. Chem. Chem. Phys. 2020, 22, 7169-7192.

[5] R. Ahlrichs, M. Bär, M. Häser, H. Horn, C. Kölmel, Chem. Phys. Lett. 1989, 162, 165-169.

[6] S. Grimme, J. G. Brandenburg, C. Bannwarth, A. Hansen, J. Chem. Phys. 2015, 143, 054107.

[7] A Klamt, G Schüürmann, J. Chem. Soc. Perkin Trans. 2 1993, 799-805.

[8] J.-D. Chai, M. Head-Gordon, J. Chem. Phys. 2008, 128, 084106.

[9] S. Grimme, J. Antony, S. Ehrlich, H. Krieg, J. Chem. Phys. 2010, 132, 154104.

[10] F. Weigend, R. Ahlrichs, Phys. Chem. Chem. Phys. 2005, 7, 3297.

[11] F. Neese, Wiley Interdiscip. Rev. Comp. Mol. Sci. 2018, 8, e1327.

[12] F. Eckert, A. Klamt, AIChE J. 2002, 48, 369-385.

[13] COSMOtherm Program Suite COSMOlogic GmbH \& Co KG.

[14] S. Grimme, Chem. Eur. J. 2012, 18, 9955-9964.

[15] C. P. Kelly, C. J. Cramer, D. G. Truhlar, J. Phys. Chem. B 2007, 111, 408-422.

[16] A. V. Marenich, C. J. Cramer, D. G. Truhlar, J. Phys. Chem. B 2009, 113, 6378-6396.

[17] Handbook of Organic Solvent Properties, Elsevier, 1996.

[18] Q. Liu, L. Zhang, L. Liu, J. Du, Q. Meng, R. Gani, Chem. Eng. Sci. 2019, 202, 300-317.

[19] K. Kitaura, E. Ikeo, T. Asada, T. Nakano, M. Uebayasi, Chem. Phys. Lett. 1999, 313, 701-706.

[20] K. Kitaura, K. Morokuma, Int. J. Quantum Chem. 1976, 10, 325-340.

[21] M. W. Schmidt, K. K. Baldridge, J. A. Boatz, S. T. Elbert, M. S. Gordon, J. H. Jensen, S. Koseki, N. Matsunaga, K. A. Nguyen, S. Su, T. L. Windus, M. Dupuis, J. A. Montgomery, J. Comput. Chem. 1993, 14, 1347-1363.

[22] I. Lyskov, M. Kleinschmidt, C. M. Marian, J. Chem. Phys. 2016, 144, 034104.

[23] B. G. Levine, C. Ko, J. Quenneville, T. J. MartÍnez, Mol. Phys. 2006, 104, 1039-1051.

[24] A. D. Becke, J. Chem. Phys. 1993, 98, 1372-1377.

[25] M. Kleinschmidt, C. M. Marian, M. Waletzke, S. Grimme, J. Chem. Phys. 2009, 130, 044708.

[26] S. Miertus, J. Tomasi, Chem. Phys. 1982, 65, 239-245.

[27] J. L. Pascual-ahuir, E. Silla, I. Tuñon, J. Comput. Chem. 1994, 15, 1127-1138.

[28] R. Improta, G. Scalmani, M. J. Frisch, V. Barone, J. Chem. Phys. 2007, 127, 074504.

[29] M. J. Frisch, G. W. Trucks, H. B. Schlegel, G. E. Scuseria, M. A. Robb, J. R. Cheeseman, G. Scalmani, V. Barone, G. A. Petersson, H. Nakatsuji, X. Li, M. Caricato, A. V. Marenich, J. Bloino, B. G. Janesko, R. Gomperts, B. Mennucci, H. P. Hratchian, J. V. Ortiz, A. F. Izmaylov, J. L. Sonnenberg, D. Williams-Young, F. Ding, F. Lipparini, F. Egidi, J. Goings, B. Peng, A. Petrone, T. Henderson, D. Ranasinghe, V. G. Zakrzewski, J. Gao, N. Rega, G. Zheng, W. Liang, M. Hada, M. Ehara, K. Toyota, R. Fukuda, J. Hasegawa, M. Ishida, T. Nakajima, Y. Honda, O. Kitao, H. Nakai, T. Vreven, K. Throssell, J. Montgomery, J. A., J. E. Peralta, F. Ogliaro, M. J. Bearpark, J. J. Heyd, E. N. Brothers, K. N. Kudin, V. N. Staroverov, T. A. Keith, R. Kobayashi, J. Normand, K. Raghavachari, A. P. Rendell, J. C. Burant, S. S. Iyengar, J. Tomasi, M. Cossi, J. M. Millam, M. Klene, C. Adamo, R. Cammi, J. W. Ochterski, R. L. Martin, K. Morokuma, O. Farkas, J. B. Foresman, D. J. Fox, Gaussian16 Revision A.03, Wallingford, CT, 2016.

[30] Y. Zhao, D. G. Truhlar, Theor. Chem. Acc. 2008, 120, 215-241.

[31] A. D. Becke, J. Chem. Phys. 1993, 98, 5648-5652.

[32] T. Yanai, D. P. Tew, N. C. Handy, Chem. Phys. Lett. 2004, 393, 51-57.

[33] M. Casanova-Páez, M. B. Dardis, L. Goerigk, J. Chem. Theory Comput. 2019, 15, 4735-4744.

[34] G. Bussi, D. Donadio, M. Parrinello, J. Chem. Phys. 2007, 126, 014101.

[35] H. J. C. Berendsen, J. P. M. Postma, W. F. van Gunsteren, A. DiNola, J. R. Haak, J. Chem. Phys. 1984, 81, 3684-3690.

[36] A. Rodriguez, A. Laio, Science 2014, 344, 1492-1496. 